\title{
El derecho de retiro como herramienta \\ de gobierno corporativo: análisis empírico del caso chileno*
}

\section{Guillermo Caballero Germain * 1 Jaime Lavín Salazar ${ }^{* * *}$}

Resumen. La tesis de este trabajo es que las reglas establecidas en la legislación chilena sobre la determinación del precio de las acciones en el derecho de retiro son disfuncionales con respecto al interés tutelado. En cuanto al valor en libros, la evidencia empírica muestra que, en promedio, el precio de la acción equivale a un $53 \%$ del precio promedio bursátil. Sin embargo, esta última forma de cálculo tampoco está exenta de distorsiones. A fin de mitigar los problemas de gobierno corporativo asociados al ejercicio del derecho de retiro se propone adoptar como forma de determinación del precio el "valor ajustado".

Palabras clave: sociedad anónima, derecho de retiro, valor económico, valor ajustado.

* Fecha de recepción: 25 de octubre de 2017. Fecha de aceptación: 30 de abril de 2018.

Para citar el artículo: Caballero Germain, G. y Lavín Salazar, J., "El derecho de retiro como herramienta de gobierno corporativo: análisis empírico del caso chileno", Revista de Derecho Privado, Universidad Externado de Colombia, n. ${ }^{\circ} 35$, julio-diciembre de 2018, 205-242. DoI: https://doi.org/Io.1860 I/o I 234366.n35.08

Este trabajo se ha realizado con el apoyo de los Fondos Concursables 2014 del Centro de Gobiernos Corporativos de la Pontificia Universidad Católica de Chile (cGC Uc). Agradecemos los comentarios realizados a versiones previas de este trabajo por los profesores Fernando Atria, Osvaldo Lagos, Diego Pardow, Agustín Barroilhet y los miembros del cGc uc. Cualquier error es de nuestra exclusiva responsabilidad.

** Abogado. Doctor en Derecho. Profesor de Derecho Comercial de la Universidad de Chile, Santiago de Chile, Chile. Contacto: gcaballero@derecho.uchile.cl

*** Ingeniero Civil Industrial. Doctor en Management. Profesor asociado de Finanzas de la Universidad Adolfo Ibáñez, Santiago de Chile, Chile. Contacto: jaime.lavin@uai.cl 


\title{
Appraisal Right as a Tool for Corporate Governance: Critical Review of the Chilean Case
}

\begin{abstract}
The thesis of this paper is that the existing rules in the Chilean legislation on setting the price of shares in the appraisal right are dysfunctional to the protected interest. Regarding the book value, the empirical evidence shows that on average, this corresponds to $53 \%$ of the average stock price. However, the latter form of estimation is not exempt from distortions. A reform should establish the "fair value" as a normative criterion for adequate protection of the dissenting shareholder.
\end{abstract}

Keywords: Corporation, appraisal right, economic value, fair value.

Sumario. Introducción. I. El derecho de retiro como un problema de gobierno corporativo. A. El gobierno corporativo y la tutela del accionista minoritario. B. La determinación del precio a pagar al accionista disidente en el ordenamiento chileno. II. Estudio empírico del precio a pagar al accionista disidente en el mercado nacional. A. El ejercicio del derecho de retiro en sociedades anónimas abiertas chilenas. B. Análisis empírico de la relación bolsa-libros. III. La necesidad de reforma del diseño legal vigente. A. El derecho de retiro y la cotización bursátil. B. El derecho de retiro y la valoración de una firma. Iv. El valor ajustado como nueva regla de determinación del precio a pagar por la sociedad. A. La libertad de acuerdo entre el accionista disidente y la sociedad. B. El precio de mercado de las acciones. C. La deferencia a la lex artis financiera. v. El valor ajustado como instrumento de mejora del gobierno corporativo. A. La contribución del valor ajustado a un mejor gobierno corporativo. B. Hacia un mercado de derechos de retiro para las sociedades anónimas abiertas. Referencias.

\section{Introducción}

La tesis central de esta investigación es que las reglas vigentes sobre la determinación del precio de las acciones con ocasión del ejercicio del derecho de retiro, contenidas en la ley de sociedades anónimas chilena $\left(\mathrm{LSA}^{\mathrm{I}}\right)$, son disfuncionales con respecto al interés tutelado, y que ello impacta negativamente en el gobierno corporativo de una sociedad anónima abierta, pues, como se explicará más adelante, la cuestión central del derecho de retiro es la determinación del precio a pagar al accionista disidente ${ }^{2}$.

I Ley i 8.046. Publicada 22 de octubre de i98 I, Santiago, Chile.

2 Quedan fuera de este estudio las sociedades anónimas cerradas, así como otros aspectos del derecho de retiro, distintos a la determinación del precio a pagar por la sociedad. 
Para sustentar esta tesis, el trabajo se ordena en seis secciones, según se describe seguidamente. La determinación del nivel de protección de un accionista minoritario frente a la imposición por una mayoría de una reforma significativa de los estatutos sociales (p. ej., una fusión o la creación de una serie de acciones preferentes) responde a consideraciones políticas, económicas y jurídicas, en nuestro ordenamiento compendiadas en la regulación del derecho de retiro (I). En este, el elemento central de la protección del accionista disidente, es la compra forzosa de las acciones por parte de la sociedad. Se trata de una tutela (económica) del accionista minoritario frente al derecho (político) de la mayoría a imponer una decisión societaria trascendental 3 . Sin embargo, el cálculo del precio conforme al valor en libros - un criterio puramente contable- usualmente vacía esa tutela económica, según hemos comprobado por medio de un análisis empírico en un período de ro años para una muestra de roo acciones chilenas, cuyos datos mensuales fueron recolectados a mano (II). El cálculo del precio de las acciones a valor en libros (y, en algunos supuestos, también conforme a un promedio de la transacción bursátil) no se ajusta a la práctica financiera actual $y$, en consecuencia, se presta para comportamientos estratégicos tanto por parte de accionistas mayoritarios como minoritarios (III). Una reforma en la materia es indispensable (IV), y ella se propone mediante una compensación al accionista disidente de acuerdo al valor económico de las acciones (valor ajustado). Una consecuencia natural de nuestra propuesta sobre la forma de cálculo del precio a pagar al accionista disidente conforme al valor ajustado es una doble mejora al gobierno corporativo, al aumentar la tutela y los incentivos de los accionistas minoritarios y sujetar el precio ofrecido por la sociedad al escrutinio del mercado, según se explica en la parte final (v) de este trabajo.

3 Si bien las expresiones "accionista disidente" y "accionista minoritario" no son sinónimas, a los efectos de este trabajo las entenderemos coincidentes. En un escenario de fuerte concentración de capital y altos quorums de aprobación de los acuerdos de la junta de accionistas generadores del derecho de retiro, como sucede en nuestro país, los accionistas disidentes suelen ser también minoritarios. Sobre las características del mercado chileno, cfr. Majluf, N. Abarca; D. Rodríguez y L. Fuentes, "Governance and ownership structure in Chilean economic groups", en Revista Abante, I, I 998, I I I- I I 5; Lefort, F. y E. WALker, "Ownership and capital structure of Chilean conglomerates fact and hypothesis in Chile", en Revista Abante, I, 2000, 7; Agosin, M. y E. Pastén, Corporate governance in Chile, Documentos de Trabajo, Banco Central de Chile, 209, 2003, I-5; World Bank, Corporate Governance Country Assessment Chile, Report on the Observance of Standards and Codes, 2003, 2, disponible en: https://openknowledge.worldbank.org/ handle/ro986/I 4493 [consultado el 23 de octubre de 20 I 7]; Lefort, F. y E. WALkER, The Effect of Corporate Governance Practices on Company Market Valuation and Payout Policy in Chile, Research Network Working Paper, Inter-American Development Bank, 2005, I6, disponible en: http:// www.iadb.org/res/laresnetwork/files/pr2 2 I finaldraft.pdf [consultado el 23 de octubre de 20 I 7 ]. 


\section{El derecho de retiro como un problema de gobierno corporativo}

\section{A. El gobierno corporativo y la tutela del accionista minoritario}

\section{La estructura organizacional de la sociedad anónima y los problemas de agencia}

A partir del siglo xix, y en la medida que la actividad económica exigió mayores recursos y especialización, la sociedad anónima adquirió protagonismo en el mercado, hasta convertirse en el vehículo jurídico de inversión por antonomasia. Si bien la sociedad anónima presenta importantes ventajas para los operadores económicos (entre ellas, la personalidad jurídica, la limitación de responsabilidad y propiedad de los accionistas, la administración a cargo de un directorio y la transferibilidad de las acciones ${ }^{4}$ ), también presenta ciertos problemas. Circunscribiéndonos a lo que ahora más nos interesa, la separación estructural entre propiedad y control, si bien minimiza los costos de coordinación en la toma de decisiones por parte de una pluralidad de accionistas, crea las condiciones para que los administradores (agente) busquen satisfacer intereses divergentes de los de los accionistas (principal), generando los denominados costos de agencia 5 . La fisonomía del problema de agencia varía en una sociedad anónima con capital concentrado. Si bien un controlador tendrá suficientes incentivos para monitorear la actuación de los administradores, el problema de agencia no desaparece sino que se traslada a la relación entre accionistas mayoritarios (agente) y minoritarios (principal) 6 .

La minimización de los problemas de agencia tiene efectos positivos, pues mientras mayor sea la protección legal de los accionistas minoritarios (y acreedores), más dispuestos estarán los inversores a proveer capital a las firmas a un menor costo, aumentando de este modo no solo la eficiencia, sino también el valor económico de las empresas7. Todavía más, una rebaja en los costos de agencia genera beneficios a nivel agregado, tanto para las firmas como para el país. En el caso de las firmas, la evidencia muestra que en países emergentes aumenta el

4 Armour, J., Hansmann, H. y Kraakman, R., "What is Corporate Law", en Kraakman, R. et al., The Anatomy of Corporate Law. A Comparative and Functional Approach, 2. ${ }^{a}$ ed., Oxford, Oxford University Press, 2009, 5 .

5 Harris, M. y Raviv, A., "Corporate governance: Voting rights and majority rules", en fournal of Financial Economics, 20, I 988, 203-205; Shleifer, A. y Wolfenzon, D., "Investor Protection and Equity Markets”, en fournal of Financial Economics, 66, I, 2002, 739.

6 Armour, J., Hansmann, H. y Kraakman, R., "Agency problems and legal strategies", en Kraakman, R. et al., The Anatomy of Corporate Law. A Comparative and Functional Approach, 2. ed., Oxford, Oxford University Press, 2009, 35-36.

7 Shleifer, A. y Wolfenzon, D., "Investor protection and equity markets", en fournal of Financial Economics, 66, I, 2002, 3-5; La Porta, R., López De Silanes, F., Shleifer, A. y Vishny, R., "Legal determinants of external finance", 52 The fournal of Finance, 3, I I 3 I-I I 33. 
acceso a financiamiento, disminuye el costo de capital, mejora el desempeño y favorece un mejor tratamiento para todos los stakebolders ${ }^{8}$. En términos de país, los beneficios derivan de una mejor asignación de recursos en la economía -una de las funciones primordiales del mercado-, con el consiguiente efecto positivo en el desarrollo financiero y el crecimiento nacional9. Por todo lo anterior, desde hace algún tiempo, los problemas de agencia en el interior de la sociedad anónima abierta han adquirido notoriedad, debido al impacto en el buen funcionamiento del mercado de valores.

$\mathrm{Al}$ hilo de lo expuesto, conviene recordar que la distribución de poder dentro de una firma (en nuestro caso, bajo la forma de una sociedad anónima) y la búsqueda de equilibrios entre los distintos intereses en juego (administradores, accionistas - mayoritarios y minoritarios- y stakeholders), a fin de generar valor para todos ellos, ha sido la preocupación fundamental del debate sobre gobierno corporativo en las últimas décadas ${ }^{\mathrm{IO}}$. No obstante existir, por una parte, diversas opiniones acerca de cómo estructurar un buen gobierno corporativo y, por otra parte, diferencias en el diseño normativo a nivel local, paulatinamente se ha generado un consenso acerca de ciertos principios de buen gobierno corporativo. En esa labor de búsqueda de criterios comunes de gobernanza les ha correspondido un papel crucial, junto a la doctrina, a las organizaciones internacionales interesadas en promover el comercio transfronterizo. En este sentido, debe destacarse la labor de la Organización para la Cooperación y el Desarrollo Económicos (ocDE) en la elaboración de unos Principios de Gobierno Corporativo, cuyo amplio reconocimiento ha contribuido a la convergencia de las legislaciones locales. Sin ir más lejos, nuestro país en años recientes ha reformado la

8 Klapper, L. y Love, I., "Corporate governance, investor protection, and performance in emerging markets", en fournal of Corporate Finance, io, 5, 2004, 703-706; Claessens, S. y Yurtoglu, B., "Corporate governance in emerging markets: A survey", en Emerging Markets Review, I 5, $2013,2$.

9 La Porta, R., López De Silanes, F., Schleifer, A. y Vishny, R., "Legal determinants of external finance", en Fournal of Finance, 52, 3, I 997, I I 3 I-I I 33; Beck, T. y Levine, R., "Stock markets, banks, and growth: Panel evidence", en fournal of Banking \& Finance, 28, 3, 2004, 423-425; Levine, R., "Finance and growth: Theory and evidence", en Aghion, P. y Durlauf, S. (eds.), Handbook of Economic Growth, I, Elsevier, 2005, 865-866.

Io La literatura sobre gobierno corporativo es ingente, prueba de lo cual es la aparición de compilaciones de los textos más significativos en la materia, como, por ejemplo, Romano, R., Foundations of Corporate Law, New York, Foundation Press, I 993 y Clarke, T., Theories of Corporate Governance. The Philosophical Foundations of Corporate Governance, New York, Routledge, reimp., 2007. Para una visión general en Chile, cfr. Eyzaguirre, C., "Introducción al 'corporate governance", memoria de prueba, Universidad de Chile, inédita, 200 I; Contreras, R., "Gobierno, gestión y ética corporativa: análisis y recomendaciones", memoria de prueba, Universidad de Chile, 2005; IsLa, G., "Gobierno corporativo: teoría económica, principios de la ocDE y la Ley 20.382 ”, en Wilenmann, J. (coord.), Gobiernos corporativos, Santiago de Chile, Thomson Reuters, 201 I , 9-44. 
ley de sociedades anónimas para incorporar (parcialmente) esos principios y de esa manera cumplir con los estándares internacionales ${ }^{\mathrm{II}}$.

El derecho de retiro es una herramienta de gobierno corporativo expresamente recomendada en los Principios de Gobierno Corporativo ocde y recogida en nuestro ordenamiento, según explicaremos seguidamente ${ }^{\mathrm{I} 2}$.

\section{La noción y la función del derecho de retiro}

\section{a. La fisonomía societaria del derecho de retiro}

i. El principio mayoritario y los accionistas disidentes

La sociedad anónima no es un "contrato completo" -esto es, un negocio jurídico que establezca las conductas debidas de las partes en todas y cada una de las situaciones posibles-, y por ello es necesario prever unos mecanismos para la toma de decisiones durante la vida de la sociedad. La junta de accionistas es el órgano de la sociedad que reúne a los accionistas y en el seno del cual se deben resolver las materias más relevantes para la vida social no previstas en el pacto social, completando de esa manera el negocio societario en aquellos aspectos no acordados inicialmente por los accionistas ${ }^{\mathrm{I} 3}$.

En los primeros tiempos de la sociedad anónima, una modificación substancial al estatuto social requería de la aprobación de cada accionista ${ }^{\mathrm{I}}$. Sin embargo, la exigencia de unanimidad pone en manos de cualquier accionista un poder excesivo y paralizante de la gestión social, lo cual resulta ineficiente como mecanismo de gobierno. Ahora bien, aunque la regla de mayoría parece más efi-

I I Así consta en Biblioteca del Congreso Nacional de Chile, "Historia de la Ley i 9.705", 575, disponible en: https://www.leychile.cl/Navegar?idNorma= 79295 \&buscar= 19705 [consultado el 23 de octubre de 2017] y en Biblioteca del Congreso Nacional de Chile, "Historia de la Ley 20.382", I94-206, disponible en: https://www.leychile.cl/Navegar?idNorma=1007297\&busc $\operatorname{ar}=20382$ [consultado el el 23 de octubre de 2017 ].

I G2O/oecd, Principles of Corporate Governance, Paris, oEcD, 20 I 5, 27, disponible en: http://www. iadb.org/res/laresnetwork/files/pr22 Ifinaldraft.pdf. [consultado el 23 de octubre de 20I7]; "Historia de la Ley I9.705", 5, disponible en: https://www.leychile.cl/Navegar?idNorma= I 79295\&buscar=I9705 [consultado el 23 de octubre de 20I7]; BERnet, M., "El gobierno de las sociedades abiertas", en Revista de Derecho (Valdivia), 9, disponible en: http://www.scielo. cl/scielo.php? script=sci_arttext\&pid=So7 I 8-09502004000 I 00002 \&lng=es\&nrm=iso\&tlng =es [consultado el 23 de octubre de 2017 ].

I 3 Easterbrook, F. y Fischel, D., The Economic Structure of Corporate Law, Cambridge, Harvard University Press, I991, 403.

I4 En la doctrina estadounidense, Carney, W., "Fundamental corporate changes, minority shareholders, and business purposes", en American Bar Foundation Research Journal, 5, I, I980, 78; Manning, B., "The shareholder's appraisal remedy: An essay for Frank Coker", en Yale Law Fournal, 72, I962, 247 nota 38; Wertheimer, B., "The purposes of the shareholders' appraisal remedy”, en Tennessee Law Review, 65, I997-1998, 665-666. Para la evolución europea, Dasso, A., Tratado del derecho de separación o receso del socio y del accionista, Buenos Aires, Legis, 20 I 2, 6-8. 
ciente que el criterio de unanimidad, tampoco está exenta de críticas: en efecto, las decisiones de mayoría impiden aprovechar las ventajas del consentimiento como mecanismo contractual típico destinado a garantizar la tutela de cada socio, tal como ocurre en el momento de la constitución de una sociedad anónima. Es más, al imponer la mayoría una decisión al resto de los accionistas, el grupo mayoritario decide sobre el uso de los bienes sociales en términos distintos a los que ex ante podrían haberse acordado por los accionistas en el momento de la constitución (regla de unanimidad), generándose fuertes incentivos para que una mayoría posteriormente pueda expoliar a los accionistas minoritarios.

Por lo anterior, el derecho de retiro sirve, especialmente en sociedades con capital concentrado, como una herramienta legal para mitigar el problema de agencia entre accionistas mayoritarios y minoritarios ${ }^{15}$. En efecto, dado que en una sociedad con capital concentrado las decisiones de la junta de accionistas son fuertemente influidas (o directamente decididas) por el grupo controlador, el derecho de retiro constituye un mecanismo de protección del accionista minoritario frente a eventuales abusos de la mayoría.

\section{ii. La naturaleza forzosa de la venta}

El ejercicio del derecho de retiro es una decisión potestativa del accionista disidente. Sin embargo, el resultado de esa decisión es un contrato forzoso heterodoxo para la sociedad: la celebración de una compraventa donde las partes, la cosa y el precio están determinados legalmente ${ }^{\mathrm{r}}$.

Como se desprende de lo anterior, la compraventa de las acciones de un accionista disidente no es una operación realizada libremente en el mercado (transacción externa), sino una operación en el interior de una sociedad en unos términos fijados legalmente (transacción interna) ${ }^{17}$.

i5 Armour, J., Hansmann, H. y Kraakman, R., "Agency problems and legal strategies", en Kraakman, R. et al., The Anatomy of Corporate Law. A Comparative and Functional Approach, 2. ${ }^{a}$ ed., Oxford, Oxford University Press, 2009, 39-4I; Rock, E., Davies, P., Hideki, K. y Kraakman, R., "Fundamenatl Changes", en Krahkman, R. et al., The Anatomy of Corporate Law. A Comparative and Functional Approach, 2. ${ }^{\mathrm{a}}$ ed., Oxford University Press, Oxford, 2009, r9 r. Para la discusión en un contexto normativo diverso, cfr. Kanda, H. y Levmore, S., "The appraisal remedy and the goals of Corporate Law", en UCLA Law Review, 32, 1984-1985, passim.

i6 López, J., Los contratos, Santiago de Chile, Jurídica de Chile, 2005, I 75. En ese sentido, cfr. Superintendencia de Valores y Seguros, Oficio Ordinario 25.013 de 2014.

I7 Esta distinción es usual en la doctrina especializada: cfr. MolL, D., "Shareholders oppression and 'fair value': Of discounts, date, and dastardly deeds in the close corporations", en Duke Law fournal, 54, 2, 2004, 3 19-325; PAz-Ares, C. y Perdices, A., "Lógica y límites de los descuentos por iliquidez y minoría en la valoración de participaciones sociales", en Revista Española de Capital Riesgo, 2, 2010, 6 . 
El carácter forzoso de la compraventa derivada del ejercicio del derecho de retiro justifica la construcción del precio a pagar al accionista disidente bajo unos criterios distintos a los del mercado ${ }^{18}$.

\section{iii. La naturaleza disolutiva del derecho de retiro}

La doctrina mayoritaria entiende el ejercicio del derecho de retiro de un accionista disidente como una hipótesis de disolución parcial de una sociedad anónima ${ }^{19}$. El retiro de un accionista significa el término de su pertenencia a la sociedad, la restitución de sus aportes y el cobro, en su caso, de la respectiva utilidad, todo lo cual se sintetiza en el pago del valor de sus acciones. A esos efectos, la sociedad está autorizada para adquirir acciones de propia emisión, disminuyéndose el capital de pleno derecho, salvo que la sociedad las enajene en bolsa en el plazo de un año desde la adquisición (art. 27 LSA).

Tanto la liquidación como el derecho de retiro son mecanismos para devolver al accionista el capital y, en su caso, las utilidades pendientes de distribución, aunque también presentan diferencias. La liquidación es una operación siempre colectiva; en cambio, el derecho de retiro es una operación individual. La hipótesis de estar la empresa en marcha hace parte de la naturaleza en la liquidación $y$, en cambio, en el derecho de retiro es un elemento esencial ${ }^{20}$.

Una objeción a la naturaleza disolutiva del derecho de retiro puede proponerse del modo siguiente: el valor de una empresa en liquidación es menor al de una empresa en explotación (Going Concern Value), de modo que con este régimen se perjudicaría al accionista disidente, al no obtener este el valor propor-

I8 Este es precisamente el sentido de la distinción y opción de política jurídica a favor del "fair value" y no del "fair market value" como criterio de determinación del precio a pagar al accionista disidente; cfr. Molt, D., "Shareholders oppression and 'fair value': Of discounts, date, and dastardly deeds in the close corporations", en Duke Law fournal, 54, 2, 2004, 31 19-32 5; Hunter, C. y Pearce, C., "Corporate governance: Voting rights and majority rules", en Annual Review of Civil Litigation, 201 I, 30.

i9 Puelma,A., Sociedades, $3 .{ }^{a}$ ed., Santiago de Chile, Jurídica de Chile, 2003, t. II, 59 I-696; Olavarría, J., Manual de derecho comercial, Barcelona, Clarasó, I969, 427; Alcalde, E., "Resolución parcial y exclusión de un accionista en la sociedad anónima", en El Mercurio Legal, 20I 4, disponible en: http://www.elmercurio.com/Legal/Noticias/Analisis-Juridico/2014/o3/o3/Resolucion-parcial -y-exclusion-de-un-accionista-en-la-sociedad-anonima.aspx [consultado el 23 de octubre de 20I7]. En contra, PUGa VIAL, J., La sociedad anónima y otras sociedades por acciones en el derecho chileno y comparado, Santiago de Chile, Jurídica de Chile, 20I4, t. II, 374, quien sostiene que la LSA no contempla la disolución parcial, pero entiende que el ejercicio del derecho de retiro "pone a la sociedad en un proceso de reducción de capital".

20 Que el objeto de valoración en el derecho de retiro es la empresa en marcha lo demuestra el uso del valor en libros y del precio promedio bursátil (infra I.B). En la doctrina, de entre muchos, cfr. Wertheimer, B., "The shareholders' appraisal remedy and how courts determine fair value", en Duke Law fournal, 47, 4, I998, 655; KandA, H. y Levmore, S., "The appraisal remedy and the goals of Corporate Law", en UCLA Law Review, 32, I984-1985, 442; HunTer, C. y Pearce, C., "Corporate governance: Voting rights and majority rules", en Annual Review of Civil Litigation, 201 I, 32. 
cional de la empresa en marcha, contrariándose por tanto la finalidad tutelada por el derecho de retiro. Este argumento no debe prosperar ${ }^{21}$. La liquidación de una sociedad no limita las posibles formas de valoración del patrimonio. Si bien es posible liquidar los activos vendiéndolos separadamente, no es menos cierto que la liquidación puede realizarse vendiendo la empresa como una o varias unidades económicas (ex arts. 67 n. ${ }^{\circ} 9$ LSA y 2 I 7 Ley n. ${ }^{\circ} 20.720$ de 20I4). Por lo anterior, no existe contradicción en caracterizar dogmáticamente el derecho de retiro como una forma de liquidación.

Teniendo presente todo lo anterior, el derecho de retiro puede describirse como un mecanismo para componer los intereses contrapuestos de los accionistas frente a una modificación sustancial de los estatutos sociales. Ese equilibrio se logra permitiendo a la mayoría llevar adelante ciertos cambios significativos, por una parte, y por otra parte, aislando al accionista disidente de las (en su visión) adversas consecuencias derivadas de la referida modificación, utilizando un mecanismo disolutorio consistente en obligar a la sociedad a comprar sus acciones; aunque, como se explicará acto seguido, no es la única aproximación posible.

\section{b. El derecho de retiro como una opción financiera}

El derecho de retiro puede ser analizado como una opción de venta (put) en cuanto (bajo ciertas circunstancias) otorga al accionista el derecho, si bien no la obligación, de vender un activo a un precio establecido en una fecha determinada.

El titular de una opción financiera la ejercerá si, y solo si, obtiene una ganancia ${ }^{22}$. Así, para el titular de una opción de venta (en nuestro caso, el accionista disidente), esta tendrá valor si el precio de mercado del activo subyacente (la cotización de las acciones) cae (debido a la supuesta mala decisión) bajo el precio fijado para el ejercicio de la opción (en nuestro caso, determinado legalmente), pues le permitirá vender a un precio superior al de mercado.

En suma, tanto desde una perspectiva jurídica (herramienta de gobierno corporativo) como financiera (opción put), la eficacia del derecho de retiro depende de una correcta determinación del precio a pagar por la sociedad. En otras palabras, la cuestión central del derecho de retiro es el precio a pagar por la sociedad ${ }^{23}$. Precisamente por ello es necesario prestar atención a la regulación de esta materia en nuestro ordenamiento, a la que se dedica el apartado siguiente.

2 I Conforme, Paz-Ares, C. y Perdices, A., "Lógica y límites de los descuentos por iliquidez y minoría en la valoración de participaciones sociales", en Revista Española de Capital Riesgo, 2, 20I0, 9 .

22 Hull, J., Options, Futures and Other Derivatives, New Jersey, Prentice Hall, 2009, I67-i 80.

23 Wertheimer, B., "The shareholders' appraisal remedy and how courts determine fair value", en Duke Law Journal, 47, 4, I998, 626-62 7; Black, B. y KraAKMAN, R., "A self-enforcing model of 


\section{B. La determinación del precio a pagar al accionista disidente en el ordenamiento chileno}

La LSA establece que el precio a pagar al accionistas disidente será el "valor de sus acciones" (art. 69.I, primer segmento). Esa regla general se bifurca en dos subreglas: en la sociedad anónima cerrada, el "valor en libros", y en las sociedad anónima abierta, el "valor de mercado"; en ambos casos, "determinado en la forma que fije el Reglamento" (art. 69.II LSA).

\section{El valor en libros}

El Reglamento de la LSA (RLSA ${ }^{24}$ ) establece que el valor en libros de una acción se determinará "dividiendo el patrimonio por el número total de las acciones suscritas y pagadas, de la sociedad" (art. I30.I RLSA). El valor en libros es el cociente resultante de dividir el patrimonio (dividendo) entre el número de acciones (divisor). El patrimonio de la sociedad se determinará según "las cifras del último balance que se haya presentado a la Superintendencia, o del último balance que se disponga en caso que la sociedad no deba presentar su balance ante aquélla" (art. I3O.II RLSA). El número de acciones utilizado como divisor será el existente al tiempo de la confección del referido balance (art. I 30.I RLSA).

Dado que entre la fecha del balance y la del hecho o acuerdo de la junta de accionistas detonante del derecho de retiro puede transcurrir un tiempo, el cociente original debe eventualmente ajustarse ante: i) la variación de la unidad de fomento (art. I 3 O.II RLSA), ii) el aumento del capital social (art. I 30. III RLSA) y iii) el pago de dividendos o repartos de capital (art. I3 I RLSA).

\section{El valor de mercado}

El RLSA introduce importantes novedades en la definición del "valor de mercado" para las acciones de sociedades anónimas abiertas, al distinguir según se trate de valores con o sin presencia bursátil (art. I 32 n. 2 RLSA).

Las acciones con presencia bursátil están definidas legalmente como aquellas que responden "a condiciones que, de acuerdo a la Superintendencia, sean indicativas de la liquidez de los valores o de la profundidad de los mercados en que se negocien los valores en cuestión, a efectos de propiciar una correcta formación de precios" (art. 4 bis letra g LMv) ${ }^{25}$. Esta norma legal ha sido desa-

Corporate Law", en Harvard Law Review, I09, I996, 1956-1957; DAsso, A., Tratado del derecho de separación o receso del socio y del accionista, Buenos Aires, Legis, 20 2, 557.

24 Ministerio de Hacienda, Decreto Supremo 702, publicado el 6 de julio de 2012, Santiago, Chile.

25 Artículo $5 .^{\circ}$ de la Ley $20.55^{2}$ de 201 I. 
rrollada reglamentariamente por la Comisión para el Mercado Financiero (CMF), estableciendo que la presencia bursátil puede cumplirse, o bien alcanzando una "presencia ajustada" del 25\% (cuyos mínimos están fijados legalmente), o bien si el valor cuenta con un market maker ${ }^{26}$.

El precio a pagar por acción al accionista disidente en el caso de acciones con presencia bursátil será "el promedio ponderado de las transacciones bursátiles de la acción durante el período de 60 días hábiles bursátiles comprendidos entre el trigésimo y el nonagésimo día hábil bursátil anterior a la fecha de la Junta que motiva el retiro" (art. I 32 n. ${ }^{\circ} 3$ RLSA, en adelante, también, el "precio promedio bursátil"). En cambio, si las acciones de una sociedad anónima abierta carecen de presencia bursátil, se pagará el valor en libros.

En suma, la LSA establece (inicialmente) una regla única para determinar el precio a pagar al accionista disidente: el "valor de sus acciones" (art. 69.I, primer segmento), pero acto seguido explicita unos criterios diferentes para determinar ese "valor de las acciones", según se trate de sociedades anónimas abiertas o cerradas. Para estas últimas se utiliza un concepto contable (el valor en libros). En cambio, para las sociedades anónimas abiertas se utiliza un criterio financiero (el valor de mercado de las acciones). A su turno, el RLSA amplía el ámbito de aplicación del criterio contable del valor en libros, al extenderlo a las sociedades anónimas sin presencia bursátil. Por todo lo anterior, la regla vigente puede reformularse del modo siguiente: la determinación del valor de las acciones a pagar al accionista disidente es, por regla general, el valor en libros, salvo que se trate de sociedades anónimas abiertas con presencia bursátil, en cuyo caso el valor a pagar será el precio promedio bursátil.

\section{Estudio empírico del precio a pagar al accionista disidente en el mercado nacional}

En este trabajo hemos querido comprobar empíricamente si el cálculo del precio a valor en libros compensa adecuadamente a un accionista disidente Los resultados de esas pruebas de campo se exponen en los apartados siguientes.

\section{A. El ejercicio del derecho de retiro en sociedades anónimas abiertas chilenas}

Un número total de $\mathrm{I} 42$ operaciones generaron derecho de retiro en el período 2004-20I4 para las sociedades inscritas en el registro de valores de la CMF, según la información disponible en la Bolsa de Comercio de Santiago (всs). De ellas, en 65 transacciones $(45,8 \%)$ se ofreció pagar al accionista disidente el valor

26 La "presencia ajustada" es definida en la Norma de Carácter General cmF n. 327 del I 7 de enero de 2012. 
en libros, aunque esa cifra podría estar subestimada y alcanzar rog operaciones $(76,8 \%)^{27}$.

Estas cifras muestran que el cálculo de acuerdo al valor en libros del precio a pagar por la sociedad es relevante en nuestro país en las sociedades anónimas abiertas. Tal como se menciona más adelante (II.A.2), ciertas características del mercado bursátil chileno explican la falta de liquidez suficiente de un porcentaje importante de las acciones cotizadas.

\section{B. Análisis empírico de la relación bolsa-libros}

Utilizando información financiera de la BCs y de Bloomberg, se construyó la relación bolsa-libros (вL) del mercado chileno para el universo completo de acciones cotizadas en la всs en el período I987-2016, representada en el gráfico I. La muestra arroja los resultados siguientes: i) el promedio de la relación BL para las acciones locales es de I.72 veces, con un mínimo de r.o6 y un máximo de 2.94 ; ii) durante los últimos 30 años la relación BL nunca ha sido inferior a I; iii) la relación BL ha subestimado el valor bursátil de las acciones chilenas, por cuanto en promedio equivale a un $53 \%$ del valor de mercado.

Adicionalmente, se construyó a mano una base de datos sobre una muestra de roo acciones con información mensual para el período comprendido entre enero de 2004 y diciembre de 2014 . La muestra comprende a empresas del IPSA y el IGPA, las que a diciembre de 20 I 4 equivalían al 70\% y el 90\%, respectivamente, de la capitalización bursátil local.

La tabla I indica que la media de la relación BL para la muestra es de 2.34 veces, existiendo diferencias estadísticamente significativas por tamaño y sectores económicos. En el gráfico 2 se resume la evolución a través del tiempo de este indicador. Se observa la presencia de una amplia variabilidad temporal, la que se relaciona con variables propias de cada firma y con variables del mercado accionario ${ }^{28}$. Al igual que para el universo completo de las acciones listadas, se observa que en promedio el valor en libros es inferior al valor de mercado. En el gráfico 3 se separa la muestra entre empresas con y sin presencia bursátil. Para el caso de las firmas con baja presencia, la relación BL es menor que para las empresas con alta presencia. Al igual que en los casos anteriores, la relación entre el valor en libros y el de mercado se mantiene.

27 Otras 44 operaciones no indican el valor a pagar. Si estas últimas se incluyeran como retiros en firmas sin liquidez, el porcentaje a valor en libros ascendería a un $76,8 \%$.

28 Estos resultados están en línea con la literatura financiera y la evidencia internacional: cfr. YERMACK, D., "Higher market valuation of companies with a small board of directors", en fournal of Financial Economics, 40, 2, I996, I85-187; Berger, P. y Ofek, E., "Diversification's effect on firm value", en fournal of Financial Economics, 37, I, 47-49. El análisis econométrico detallado de los datos puede ser solicitado a los autores. 


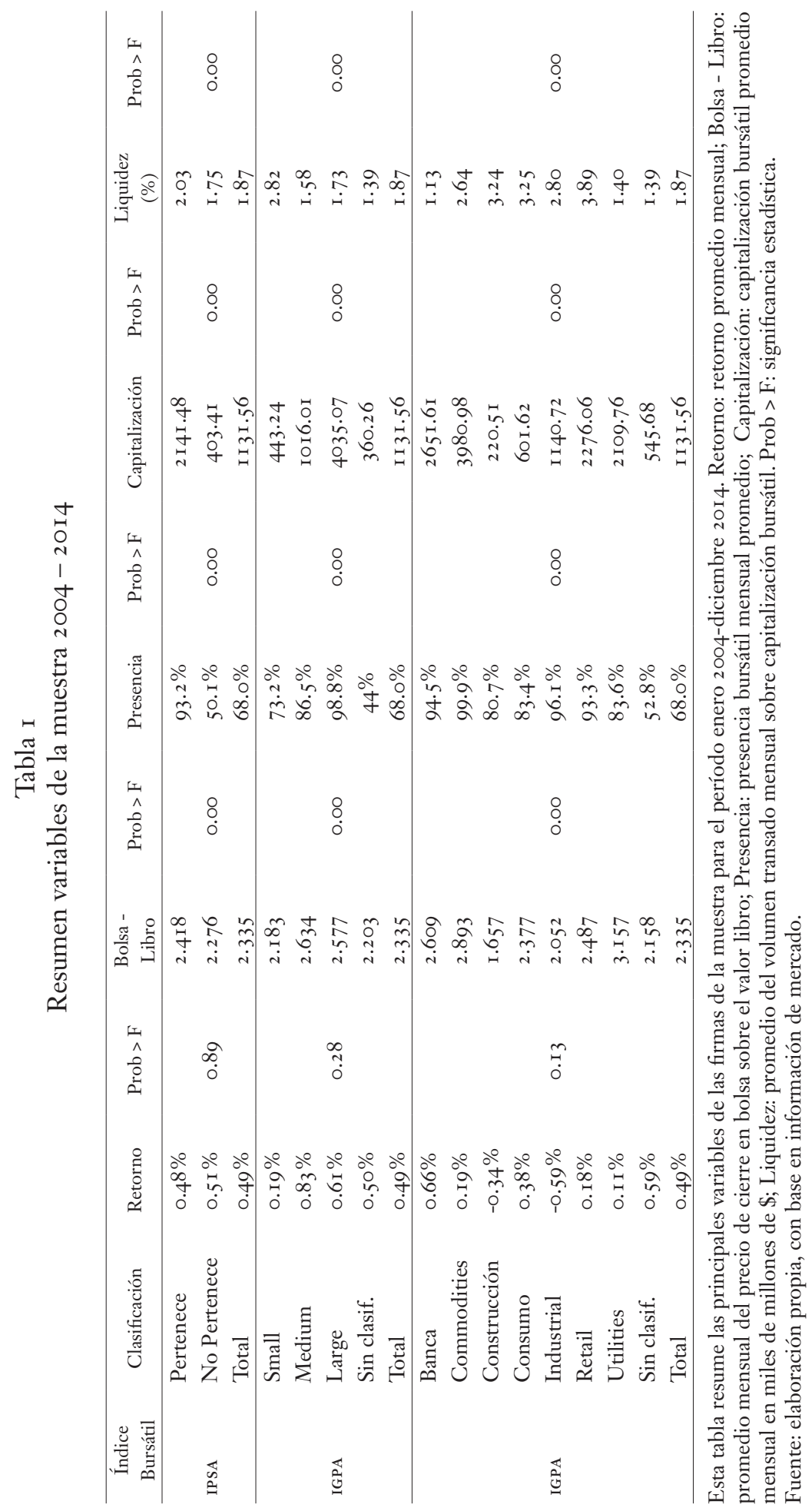


Finalmente, en la tabla 2 se desagrega la relación BL entre distintos grupos de empresas, contrastándose y estimándose con el precio promedio bursátil. La evidencia indica que la diferencia entre ambas medidas es de un $2.7 \%$, siendo esta diferencia significativa desde el punto de vista estadístico, no así en lo económico, pues la magnitud de la diferencia entre ambas medidas es pequeña.

Tabla 2

Resultados univariados

\begin{tabular}{cccc}
\hline & $(\mathrm{A})$ & $(\mathrm{B})$ & \\
& Bolsa - Libro & PM60 - Libro & Dif. \\
\hline Muestra total & 2.335 & 2.273 & $0.062^{* *}$ \\
IPSA & $2.4 \mathrm{I} 8$ & 2.323 & $0.094^{* * *}$ \\
No IPSA & 2.276 & 2.235 & 0.040 \\
IGPA Small & 2.183 & 2.079 & $0.103^{* *}$ \\
IGPA Medium & 2.634 & 2.666 & $-0.03^{2}$ \\
IGPA Large & 2.577 & 2.443 & $0.133^{* *}$ \\
IGPA- Banca & 2.609 & 2.459 & $0.150^{* * *}$ \\
IGPA - Commodities & 2.893 & 2.646 & $0.246^{*}$ \\
IGPA - Construcción & I.657 & I.43 I & $0.226^{* * *}$ \\
IGPA - Consumo & 2.377 & 2.334 & 0.042 \\
IGPA - Industrial & $2.05^{*}$ & $\mathrm{I} .805$ & $0.246^{* *}$ \\
IGPA - Retail & 2.487 & 2.407 & 0.079 \\
IGPA - Utilities & 3.157 & 3.272 & $-0.1 \mathrm{I} 4$ \\
IGPA - sin clasificación & 2.158 & $2.1 \mathrm{I} 6$ & 0.042 \\
Alta Presencia & 2.426 & 2.345 & $0.080^{* * *}$ \\
Baja Presencia & I.870 & I.860 & 0.010 \\
\hline
\end{tabular}

Esta tabla resume promedios para la muestra total, IPSA, IGPA y acciones de alta y baja presencia. Bolsa - Libro: promedio del precio de cierre en bolsa sobre el valor libro; PM6o - Libro: promedio de 60 días del precio de cierre en bolsa sobre el valor libro. Significancia estadística: ${ }^{* * *}$ al I \%; ** al $5 \%$; * al Io\%.

Fuente: elaboración propia, con base en información de mercado.

Para el caso de las firmas sin presencia bursátil no existen diferencias estadísticamente significativas entre la relación BL calculada con el precio de mercado (columna A) y aquella estimada con el precio promedio bursátil (columna B). Sin embargo, debe recordarse que el precio a pagar se calcula en ese caso conforme al valor en libros. 
En suma, al pagar al accionista disidente el valor en libros se estaría subestimando significativamente el valor de mercado de sus acciones, pues en promedio el valor en libros de las empresas sin presencia bursátil equivale al 53\% del valor bursátil (tabla 2). Asimismo, la evidencia indica que para la muestra de firmas, el precio promedio bursátil es una buena aproximación del valor bursátil de una empresa.

Gráfico I

Relación bolsa-libros en el mercado chileno, r987-2016

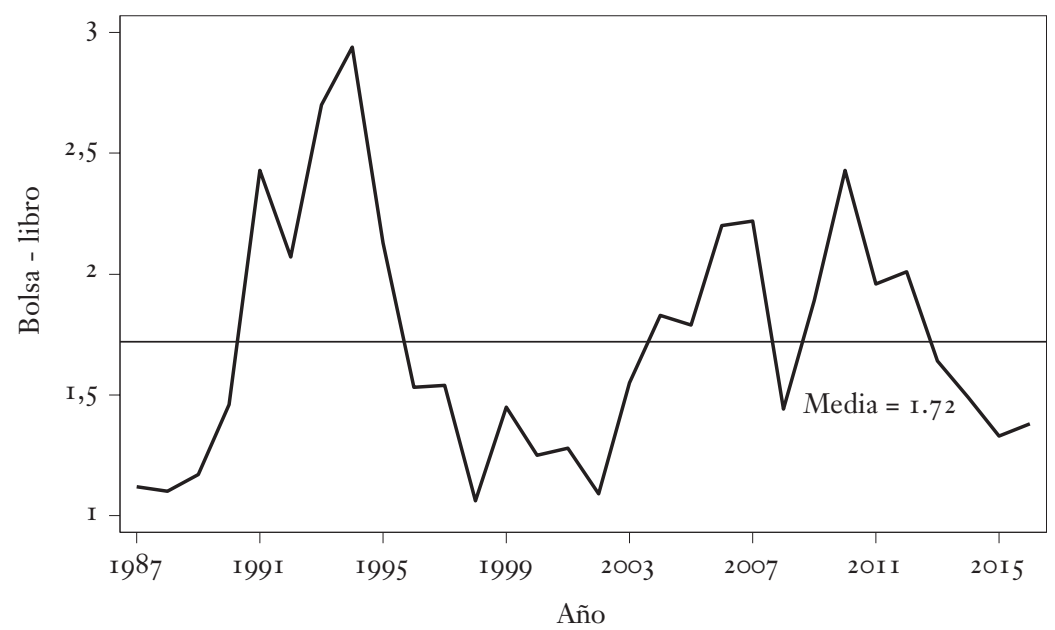

Fuente: elaboración propia, con base en información de mercado.

\section{Gráfico 2}

Relación bolsa-libros en la muestra IPSA e IGPA, 2004-20I4

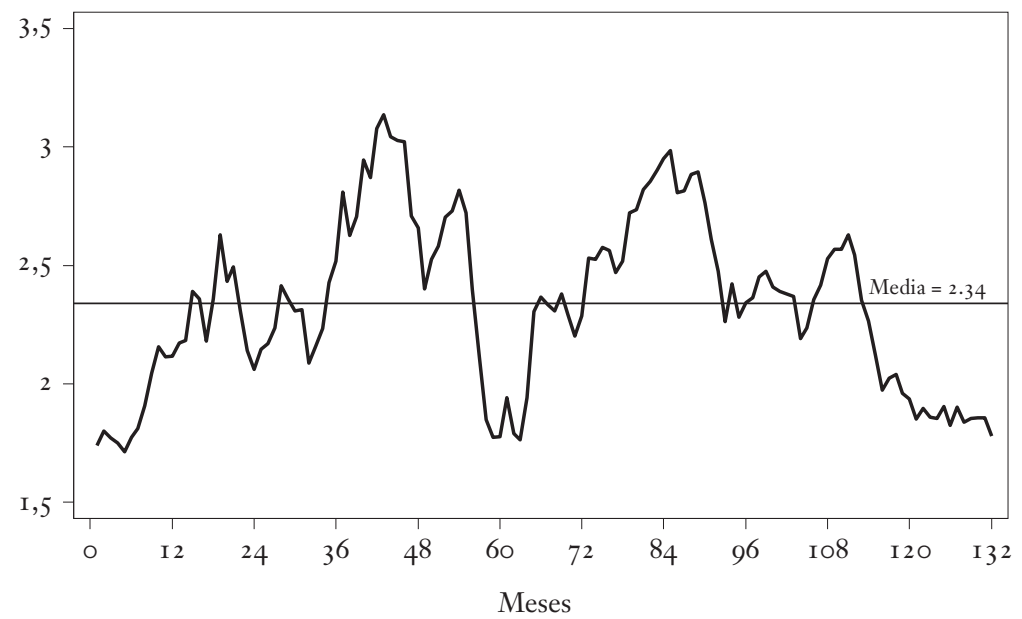

Fuente: elaboración propia, con base en información de mercado. 


\section{Gráfico 3}

Relación bolsa-libros en la muestra IPSA e IGPA, 2004-20I4 (con alta y baja presencia)

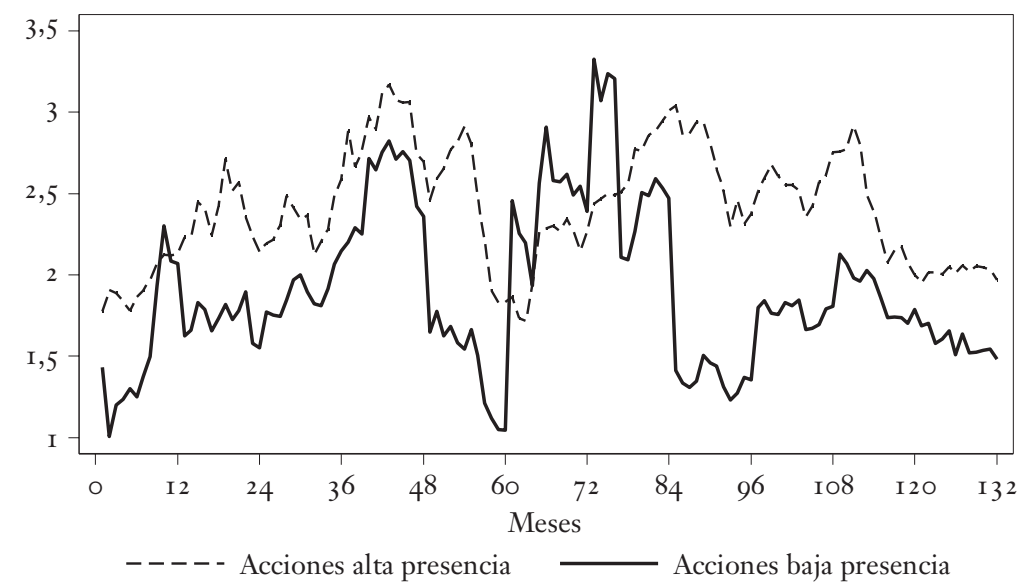

Fuente: elaboración propia, con base en información de mercado.

\section{La necesidad de reforma del diseño legal vigente}

El valor en libros y el precio promedio bursátil tienen la doble ventaja de facilitar y dar certidumbre acerca de la forma de calcular el precio a pagar al accionista. La facilidad reside en simplificar la valoración de las acciones a una simple operación aritmética. La certidumbre deriva de la imposibilidad de controversia acerca del valor de las mismas ${ }^{29}$.

La desventaja más notable de utilizar los criterios legales vigentes para calcular el precio a pagar por la sociedad es el eventual vaciamiento de contenido de la tutela ofrecida al accionista minoritario, desincentivando la inversión por parte de los mismos. Ni el valor en libros, según nos muestra la evidencia empírica descrita en el apartado anterior, ni el precio promedio bursátil, como se mostrará más adelante, reflejan necesariamente el valor económico de una empresa en marcha. Si lo anterior es cierto, entonces el régimen vigente abona el terreno para comportamientos estratégicos. La mayoría puede deliberadamente tomar ex ante decisiones en contra de los minoritarios, si estima que el ejercicio del derecho de retiro no es para estos últimos una alternativa económicamen-

29 Hasta donde tenemos información, no han existido pleitos sobre esta materia, con excepción de la jurisprudencia administrativa contenida en el Oficio Ordinario cmF n. ${ }^{\mathbf{2}}$ 23.35 I de 20 I4 (en el caso de estados financieros consolidados bajo norma IFRs de una sociedad anónima sin presencia bursátil, el cálculo del valor en libros debe considerar el denominado "Patrimonio atribuible a los propietarios de la controladora" y no el "Patrimonio total neto", que incluye la partida "Participaciones no controladoras"). 
te viable dada la forma de cálculo del precio a pagar. Como contrapartida, un accionista minoritario puede ex post oponerse a una decisión, no obstante estar de acuerdo con ella, solo para ejercer el derecho de retiro en consideración al beneficio derivado de enajenar sus acciones a la sociedad a un precio superior al valor económico de las mismas.

Teniendo en mente los resultados del estudio empírico mostrado previamente, es necesario reflexionar sobre cómo debe ser la forma de cálculo del precio a pagar al accionista disidente. Desde esa perspectiva crítica entendemos que, según se explicará seguidamente, el precio promedio bursátil aparece como una mejor fórmula de cálculo del precio a pagar por la sociedad, aunque no exenta de problemas (I). En cambio, el valor en libros, presenta graves deficiencias para servir de criterio de valoración de las acciones de una sociedad anónima abierta en el marco del derecho de retiro (2).

\section{A. El derecho de retiro y la cotización bursátil}

\section{La cotización bursátil como medida de valor}

La idea de utilizar el precio promedio bursátil -una práctica observable en otros ordenamientos jurídicos- para la determinación del precio a pagar al accionista disidente descansa sobre la premisa de la Efficient Market Hypothesis: el mercado fijará un precio mucho mejor que un juez $3^{3}$. Sin embargo, la equivalencia entre el precio promedio bursátil y el valor económico de las acciones tiene como supuestos necesarios la racionalidad de los agentes económicos y la eficiencia (valorativa) del mercado ${ }^{3}$. Los inversores no solo deben tener la capacidad de procesar la información económica y financiera existente para decidir en consecuencia, sino que además la información relativa a las empresas debe estar ampliamente disponible y a un bajo costo. Adicionalmente, se requiere que el mercado sea líquido y competitivo, con un número suficientemente grande de compradores y vendedores, de modo que nadie por sí solo pueda manipular el valor de una empresa ${ }^{32}$. Faltando estas condiciones, el precio de mercado de las

30 Esta idea fue defendida por Fama, E., "Efficient capital markets: A review of theory and empirical works", en The fournal of Finance, 25, 2, I969, 383-4I 7. En relación con el tema específico en estudio, cfr. Nota "A reconsideration of the stock market exception to the dissenting shareholder's right of appraisal”, en The Michigan Law Review Association, 74, I975-1976, 1063; Gilson, R. y Kraakman, R., "The mechanisms of market efficiency", en Virginia Law Review, 70, 4, I984, 552; Hunter, C. y Pearce, C., "Corporate governance: Voting rights and majority rules", en Annual Review of Civil Litigation, 20 I I, 36.

3 I Sobre la eficiencia valorativa del mercado, cfr. Fischel, D., "Efficient capital markets, the crush, and the fraud on the market theory", en Cornell Law Review, 74, I988-I989, 914-9 5.

32 Brudney, V., "Efficient markets and fair values in parent subsidiary mergers", en The fournal of Corporation Law, 4, I978-I 979, 64-65; Fischel, D., "The appraisal remedy in Corporate Law", en American Bar Foundation Research Fournal, 8, 4, I983, 890; Hunter, C. y Pearce, C., 
acciones se desvía de sus fundamentos económicos y, en consecuencia, de su valor económico, lo que eventualmente puede desencadenar burbujas bursátiles 33 .

Por todo lo anterior, el precio de cotización bursátil no es "una suerte de encarnación terrenal de la vieja noción teológico-moral o iusnaturalista del precio justo"34. Una cita de la Court of Chancery del Estado de Delaware puede ilustrar el punto:

When it is said that the appraisal which the market puts upon the value of the stock of an active corporation as evidenced by its daily quotations, is an accurate, fair reflection of its intrinsic value, no more than a moment's reflection is needed to refute it [...] The experience of recent years is enough to convince the most casual observer that the market in its appraisal of values must have been woefully wrong in its estimates at one time or another within the interval of a space of time so brief that fundamental conditions could not possibly have become so altered as to affect true worth 35 .

Solo agentes racionales operando en un mercado transparente, no sujeto a manipulaciones, suficientemente líquido y profundo, pueden formar correctamente precios. Sin embargo, esas premisas son difíciles de cumplir, en especial en un mercado emergente ${ }^{3}$.

\section{La presencia bursátil y la eficiencia valorativa del mercado}

La eficiencia valorativa de un mercado de valores se refiere a su capacidad para reflejar el valor económico de una empresa37. La legislación vigente asume que la presencia bursátil (medida de liquidez) es equivalente a la eficiencia valorativa. Como cuestión previa, es conveniente mencionar que el mercado financiero chileno, a pesar de ser relevante entre los países emergentes, no alcanza el tamaño ni la liquidez de los países desarrollados (ni de algunos emergentes de Asia). En particular, el mercado accionario chileno sufre de un serio problema de iliqui-

"Corporate governance: Voting rights and majority rules", en Annual Review of Civil Litigation, 20 I I, 37 .

33 Barberis, N. y Thaler, R., "A survey of behavioral finance", en Constantinides, G. et al. (eds.), Handbook of the Economics of Finance, 2, Elsevier, 2003, parte B, cap. I8, I055-1065.

34 Sánchez Andrés, A., "Cotización de valores”, en Sáenz, J., Oleo, F. y Martínez, A., (eds.), Estudios jurídicos sobre el mercado de valores, Cizur Menor, Thomson-Civitas, 2008, 834-835.

35 Chicago Corp. v. Munds, I72 A. 452, 455 (Del. Ch. I934).

36 Kearney, C., "Emerging markets research: Trends, issues and future directions", en Emerging Markets Review, I 3, 2, 2012 , I69-I 70.

37 Fischel, D., "Efficient capital markets, the crush, and the fraud on the market theory", en Cornell Law Review, 74, I988-1989, 913. 
$\operatorname{dez}^{38}$ : el $80 \%$ de las acciones se transa (solo) I 20 días hábiles de un total de 240 al año39.

Esta observación puede explicar (parcialmente) la decisión de política pública de fomentar la liquidez de nuestro mercado de valores, por ejemplo, mediante el establecimiento de un (cuestionable) beneficio tributario de exención de impuesto a las ganancias de capital derivadas de la venta de valores con presencia bursátil (art. I07 Decreto Ley n. ${ }^{\circ} 824$ de 1974).

Lo que no explica esa observación es por qué se ha escogido utilizar la presencia bursátil como criterio relevante para fundar una necesaria equivalencia entre el precio promedio bursátil y el valor a pagar al accionista disidente. Un mercado puede ser líquido y estar formando una "burbuja". La liquidez es (solo) uno de los elementos necesarios para medir la capacidad de un mercado de valores para reflejar el valor económico de una empresa (Efficient Market Hypothesis).

En nuestra opinión, el hecho de que un valor cuente con presencia bursátil no debe convertir en inatacable al precio promedio bursátil, pues bien puede no representar el valor económico de una empresa y, por consiguiente, perjudicar al accionista disidente.

Teniendo presente todo lo anterior, en nuestro mercado, el precio promedio bursátil de una acción con presencia bursátil puede estimarse un buen indicador del precio a pagar por la sociedad al accionista disidente, aunque -siempre que sea necesario- deberá depurarse de ciertas distorsiones, frecuentes e intensas en un mercado emergente y concentrado como el chileno, sobre lo cual volveremos más adelante.

\section{B. El derecho de retiro y la valoración de una firma}

Según lo indicamos, el precio a pagar por la sociedad es el núcleo del derecho de retiro. De no existir un valor de mercado (fiable), en nuestra opinión no es razonable utilizar para justipreciar las acciones de sociedades anónimas abiertas sin presencia bursátil el valor en libros, sino técnicas de valoración de empresas en marcha generalmente aceptadas en la comunidad financiera ${ }^{4}$.

38 Hernández, L. y Parro, F., "Sistema financiero y crecimiento económico en Chile”, en Revista de Estudios Públicos, 99, 2005, I05-I I 3 y doctrina citada supra nota 3.

39 La presencia bursátil para el período 2004-20I4 es en promedio de un 68\% (93\% para las acciones IPSA y $50 \%$ para las acciones no IPSA).

40 Kaplan, S. y Ruback, R., "The valuation of cash flow forecasts: An empirical analysis", The fournal of Finance, 50, 4, I995, I059-IO64; Wertheimer, B., "The shareholders' appraisal remedy and how courts determine fair value", en Duke Law fournal, 47, 4, I998, 626-62 7. 


\section{El carácter retrospectivo de la contabilidad}

La contabilidad es un insumo necesario, pero no suficiente, para el cálculo del valor económico de una empresa4 ${ }^{\mathrm{I}}$. Metodológicamente ambos son distintos y, por consiguiente, es previsible que arrojen resultados diversos.

El gráfico 4 muestra una positiva correlación entre el valor contable del patrimonio y el valor de mercado para el universo de acciones chilenas en el período I 987-20 I $6^{[42-43]}$. En otras palabras, la evolución del mercado accionario se relaciona con la evolución de los resultados contables de las empresas nacionales. Ahora bien, a pesar de esta alta correlación, ambas series de tiempo son bastante disímiles en cuanto a sus magnitudes.

El valor contable y el valor bursátil del patrimonio difieren -entre otros- en los elementos siguientes: (I) el valor reflejado en la contabilidad para los activos y pasivos no coincide con el valor estimado por el mercado financiero. La razón reside en que la contabilidad es una valoración estática, fundada en el registro de hechos pasados, que no incorpora las estimaciones de flujos futuros44; (2) el valor contable no captura la capacidad de una empresa de crear valor, entre otros factores, al no reflejar ciertos activos intangibles; y (3) esta visión retrospectiva no ha sido completamente superada por la contabilidad conforme a las Normas Internacionales de Información Financiera (IFRs, por su sigla en inglés ${ }^{45}$ ). Si bien las Ifrs establecen el "valor razonable" para la valoración de ciertos activos, no necesariamente reflejan el valor de las opciones reales implícitas en los activos y pasivos de la firma, así como tampoco las oportunidades proyectadas de cre-

4I Demsetz, H., The Economics of the Business Firm, Cambridge, Cambridge University Press, 1997, 93.

42 En Chile se implementaron las IFRs en el año 2009 y, por consiguiente, la comparación del patrimonio contable antes y después de ese año no es directa. Sin embargo, el gráfico no intenta hacer un contraste entre ambos períodos, sino mostrar la dinámica del valor del patrimonio contable y del valor de mercado.

43 El coeficiente de correlación entre ambos es de 0.93 , siendo este valor estadísticamente significativo al I \%.

44 Benston, G., "Accounting numbers and economic values", en Antitrust Bulletin, 27, 1982, I65 y 2 I 2; Fischel, D., "The appraisal remedy in Corporate Law", en American Bar Foundation Research fournal, 8, 4, 1983, 895; Gilson, R. y KraAkMan, R., "The mechanisms of market efficiency", en Virginia Law Review, 70, 4, I984, 56 I; Cohen, D., "Valuation in the context of share appraisal", en Emory Law fournal, 34, I, I985, I4I; CARNEy, W., "Fairness opinions: How fair are they and why should we do nothing about it", en Washington University Law Quarterly, 70, 2, I992, 532; Alfaro, J. y Campins, A., "La liquidación del socio que causa baja como consecuencia de sus separación o exclusión”, en Revista de Derecho Mercantil, 240, 200 I, 457; Koller, T., Goedhart, M. y Wessels, D., Valuation: Measuring and Managing the Value of Companies, New Jersey, Wiley, 2010, I03-1 32 y 235-27I; Dasso, A., Tratado del derecho de separación o receso del socio $y$ del accionista, Buenos Aires, Legis, 20 I 2, 61 5-6 6 .

45 Muñoz, A., "Determinación del valor razonable de las acciones por un tercero, en el caso de restricción estatutaria a la transmisibilidad inter-vivos", en Revista de Derecho de Sociedades, 25, 2005,302 . 
cimiento futuro de la empresa, ni el retorno proyectado de las nuevas inversiones de capital ${ }^{6}$. A las críticas anteriores se suma la potencial manipulación de la contabilidad y, por consiguiente, del valor en libros47. Un potencial inversor será desincentivado de participar en el mercado de valores si sabe que, frente a una reforma sustancial de los estatutos, la forma de cálculo del precio a pagar al accionista disidente es inconsistente con el valor económico de su inversión. En términos agregados ello aumentaría el costo de financiamiento de las empresas en bolsa, pues los inversionistas exigirán un mayor premio por riesgo, con lo que se afectaría el buen funcionamiento del mercado ${ }^{4}$.

\section{Gráfico 4}

Patrimonio a valor contable y mercado de acciones chilenas, I987-2016

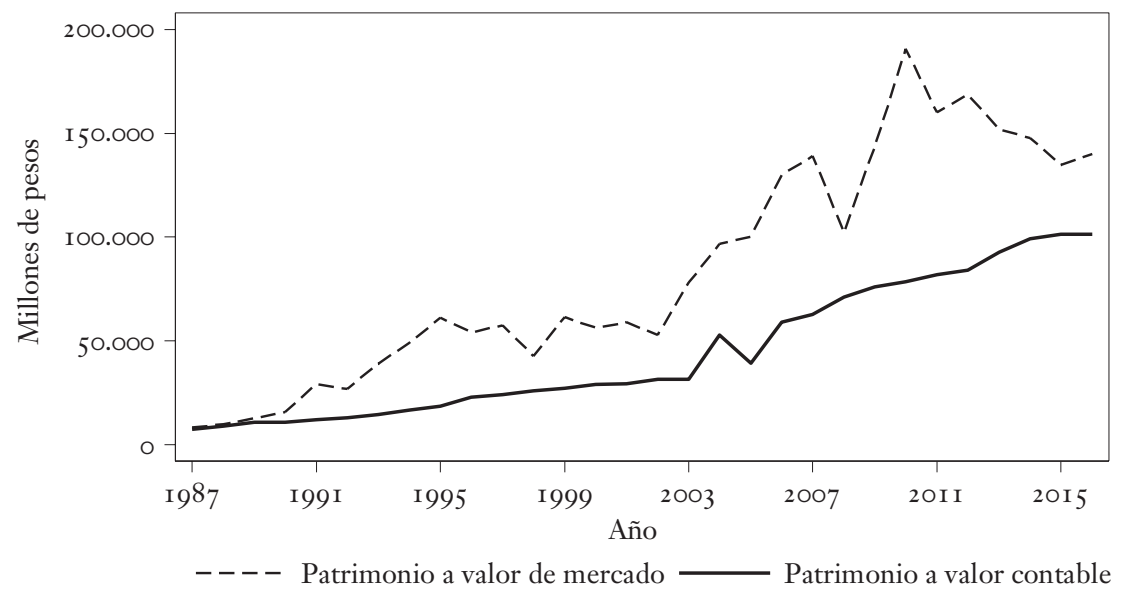

Fuente: elaboración propia, con base en información de mercado.

Todo lo anterior ha generado duras críticas de la doctrina al uso del valor en libros como criterio de determinación del precio a pagar al accionista disidente,

46 Niño, J. y Rivas, C., "La razón valor en libros-valor de mercado: el caso chileno", en Análisis Económico, I9, 42, 2004, I5 I-I 55; Fernández, P., "Company valuation methods. The most common errors in valuations", en IESE Business School, University of Navarra, 2013, I-I6, disponible en: https://is.vsfs.cz/el/64Io/leto2oI4/N_OP/um/Fernandez_20I3_Company_Valuation_Methods_SSRN-id2 74\% 20973.pdf [consultado el 23 de octubre de 20I7]; KolLER, T., Goedhart, M. y Wessels, D., Valuation: Measuring and Managing the Value of Companies, New Jersey, Wiley, 20 Io, passim. Si bien las IFrs establecen el "valor razonable" para la valoración de ciertos activos, continúan utilizando el costo histórico, por ejemplo, para la valuación inicial de propiedad, plantas y equipos (Normas de Información Contables de Chile (NICCH) I6).

47 Dasso, A., Tratado del derecho de separación o receso del socio y del accionista, Buenos Aires, Legis, $2012,560$.

48 Cohen, D., "Valuation in the context of share appraisal", en Emory Law Fournal, 34, I, 1985, I 25 . 
motivando -en algunos países- cambios jurisprudenciales o legales ${ }^{49}$. Así, por ejemplo, la Corte Suprema de Delaware sustituyó un método de valoración fundado en el pasado de una empresa ("Delaware Block Method") por uno centrado en el valor futuro de la firma ${ }^{\circ}$. En el mismo sentido, pero a través de una reforma legal, España abandonó el valor en libros, utilizando actualmente la noción de "valor razonable"5I.

Una adecuada tutela del accionista disidente exige la valoración de la empresa en marcha. En esa tarea, la contabilidad aporta información para (pero no sustituye) el cálculo del valor de las acciones conforme a criterios económicos, a lo que nos referiremos a continuación.

\section{La valuación de una empresa en marcha}

De acuerdo con la literatura financiera, entre los métodos de valuación actualmente más utilizados para empresas en marcha destacan los siguientes:

a) Valoración por múltiplos: determina el valor de una empresa en términos relativos a sus utilidades, dividendos y flujos de caja, y lo compara con empresas similares de la misma industria o sector económico (p. ej., la relación precioutilidad, la relación precio-dividendos, la relación precio-ingresos, la relación precio-valor en libros y la relación valor empresa-Ebitda (flujo de caja operacional antes de intereses, depreciación y amortización de intangibles);

b) Modelo de descuento de dividendos (DDM, por sus siglas en inglés): calcula el valor de las acciones de una empresa estimando los dividendos que esta generará y la tasa esperada de crecimiento de estos dividendos, y estima su valor presente utilizando una tasa de descuento que incorpora un premio por riesgo sobre la tasa libre de riesgo de acuerdo al riesgo de las acciones de la empresa ${ }^{52}$; y

c) Flujo de caja descontado (DCF, por sus siglas en inglés): determina el valor de una empresa a partir de la estimación de los flujos de caja futuros que generará la empresa y los descuenta al presente, utilizando una tasa de descuento que considera un premio por riesgo sobre la tasa libre de riesgo de acuerdo al riesgo de la empresa 53 .

49 Cfr., por todos, Dasso, A., Tratado del derecho de separación o receso del socio y del accionista, Buenos Aires, Legis, 20I 2, 560-569 y 590-59I; PUGA VIAL, J., La sociedad anónima y otras sociedades por acciones en el derecho chileno y comparado, t. II, Santiago de Chile, Jurídica de Chile, 20 I4, 374.

50 Weinberg v. UOP, Inc., 457 A.2d 70 I (Del. S.C. I983); Allen, W., "Securities markets as social products: The pretty efficient capital market hypothesis", en The fournal of Corporation Law, 28 , $4,2003,560$.

5 I Disposición adicional novena de la Ley 44 de 2002 (actual art. 353 del Real Decreto Legislativo I/20 Io, de 2 de julio).

52 Gordon, M. y Shapiro, E., "Capital equipment analysis: The required rate of profit", en Management Science, 3, I, I956, IO2-I IO.

53 Modigliani, F. y Miller, M., "The cost of capital, corporation finance and the theory of investment", en The American Economic Review, 48, 3, I958, 26 I-297. 
Si bien el uso de múltiplos presenta como ventaja la simplicidad y la rapidez, adolece del problema de no considerar la evolución futura de la empresa ni de su industria, como tampoco aspectos organizacionales (reorganizaciones, generación de economías de escala y de ámbito, entre otros factores) ni decisiones de inversión que incorporen las opciones reales, entre otros elementos determinantes de los flujos de caja futuros ${ }^{54}$. Adicionalmente, la valuación por múltiplos requiere el uso de datos reportados en los estados financieros y, por consiguiente, se funda en la historia de la empresa plasmada en su balance y estado de resultados, asumiendo (implícitamente) que el futuro de la empresa será similar a su pasado, lo cual es altamente discutible55.

Por su parte, la correcta utilización de los métodos de DCF y DDM para la valuación de una empresa exige la estimación detallada para cada año de sus ingresos, costos, inversiones en activos corrientes y capital de trabajo, y también de su valor residual. Así mismo, se debe determinar la tasa de descuento o de costo de capital, la que depende de la mezcla de financiamiento, del costo de los pasivos exigibles y del costo de oportunidad del patrimonio (para el DCF y el DDM). En consecuencia, su resultado final -es decir, el valor de una empresa- dependerá fuertemente de los supuestos y criterios utilizados ${ }^{5}$.

\section{El estado actual de la lex artis financiera}

Actualmente, el método de DCF es el más utilizado en la industria financiera ${ }^{57}$. Esto por cuanto, desde un punto de vista financiero, una empresa es vista como un activo generador de flujos de caja (empresa en marcha). Lo anterior se basa en el principio de creación de valor, que señala que las firmas crean valor invirtiendo capital que obtienen de los inversionistas -accionistas y bonistas- para

54 Las opciones reales se relacionan con el valor generado por las posibilidades de una empresa (p. ej., de ampliarse, esperar o abandonar), tomadas de manera activa, a medida que una firma desarrolla un negocio o proyecto.

55 Precisamente por lo anterior, la evidencia empírica muestra que su aplicación genera una gran dispersión de resultados y errores de estimación. Harbula, P., "Valuation multiples: Accuracy and drivers evidence from the european stock market", en Business Valuation Review, 28, 4, 2009, I97-198.

56 Fischel, D., "The appraisal remedy in Corporate Law", en American Bar Foundation Research fournal, 8, 4, I983, 89 .

57 Cohen, D., "Valuation in the context of share appraisal", en Emory Law fournal, 34, I, I985, I 27-I 33; Pereiro, L., "The valuation of closely-held companies in Latin America”, en Emerging Markets Review, 2, 4, 200 I, 330-370; Koller, T., Goedhart, M. y Wessels, D., "The right role of multiples in valuation", en McKinsey on Finance, I 5, 2005, 7-I I; I-I6; Deloof, M., DE Maeseneire, W. y Inghelbrecht, K., "How do investment banks value initial public offerings (IPOs)?", en fournal of Business Finance \& Accounting, 36, I-2, 2009, I30-I 34; Koller, T., GoeDHart, M. y Wessels, D., Valuation: Measuring and Managing the Value of Companies, New Jersey, Wiley, 2010, 104-108. 
generar flujos de caja futuros con tasas de retorno que exceden el costo de capital de dichos fondos $5^{8}$.

Con todo, dependiendo del tipo de empresa o industria, en la praxis el DCF puede ser complementado por el método de múltiplos (p. ej., para calibrar modelos de flujos descontados ${ }^{59}$ ) o sustituido (p. ej., para valorar firmas tecnológicas $\left.^{6 \circ}\right)$. En aquellos casos excepcionales donde no es factible aplicar DCF ni múltiplos, nuestra recomendación sería aplicar el método del valor de liquidación. En este, una empresa se valora como la diferencia entre el valor de mercado de los activos y pasivos, deduciendo además los gastos asociados a la liquidación de la empresa, tales como impuestos, gastos legales y pagos sociales, entre otros. Si bien es un método estático, constituye el valor mínimo de una empresa, y resulta una mejor estimación del valor de una empresa que el valor en libros, pues trabaja con el valor de mercado de los activos y pasivos, que no necesariamente coinciden con sus valores contables ${ }^{6 \mathrm{I}}$.

En suma, si bien en la praxis existe un predominio del DCF, ello no excluye el uso complementario o sustitutivo, según las características principales de la empresa o la industria, de otros métodos de valoración aceptados por la industria financiera.

\section{El valor ajustado como nueva regla de determinación del precio a pagar por la sociedad}

Previamente hemos mostrado cómo las reglas vigentes sobre la determinación del precio a pagar por una sociedad anónima abierta a un accionista disidente son disfuncionales con respecto al interés jurídico tutelado: en la mayoría de los casos, perjudica al accionista minoritario y, por consiguiente, es incoherente con la función tuitiva del derecho de retiro. Una reforma en la materia es imprescindible y debe estar orientada en el sentido de no perjudicar al accionista disidente, pero tampoco beneficiarlo indebidamente, afectando a la sociedad, a los demás accionistas y a los acreedores; en otras palabras, se debe intentar reducir al máximo los comportamientos estratégicos, tanto de los accionistas mayoritarios

$5^{8}$ Koller, T., Goedhart, M. y Wessels, D., Valuation: Measuring and Managing the Value of Companies, New Jersey, Wiley, 2010, IO3-I 32.

59 Liv, J., Nissim, D. у Tномаs, J., "Equity valuation using multiples", en fournal of Accounting Research, 40, I, 2002, I 36-I37; Koller, T., Goedhart, M. y Wessels, D., Valuation: Measuring and Managing the Value of Companies, New Jersey, Wiley, 2010, 313-327.

60 Lie, E. y Lie, H., "Multiples used to estimate corporate value", en Financial Analysts fournal, 58 , 2, 2002, 44-54; Kiм, M. y Ritter, J., "Valuing ipos", en fournal of Financial Economics, 53 3, I 999 , 4IO-4I4.

6I Fernández, P., "Company valuation methods. The most common errors in valuations", en IESE Business School, University of Navarra, 20I3, 5-6, disponible en: https://is.vsfs.cz/el/6410/\% 20 leto2or4/N_OP/um/Fernandez_2OI3_Company_Valuation_Methods_ssRn-id274\% 20973. pdf [consultado el 23 de octubre de 20 I 7 ]. 
como minoritarios. A continuación, bajo la noción de "valor ajustado" se describe nuestra propuesta sobre unas (nuevas) reglas de determinación del precio inspiradas por esta idea directriz.

Como cuestión previa, es conveniente establecer cuál puede ser la labor del ordenamiento jurídico en una materia, como esta, eminentemente financiera. Como se ha señalado descriptivamente: "valuation is an art rather than a science" ${ }^{2}$. Teniendo en mente esta idea, es posible entender que la función del ordenamiento jurídico es la de otorgar al accionista minoritario una tutela adicional a la que puede encontrar en el mercado y, por consiguiente, debe elaborar ciertas pautas para la determinación de un precio de las acciones dentro de un rango representativo del valor de la empresa en marcha para un periodo previo al ejercicio del derecho de retiro ${ }^{63}$. Alcanzar ese estadio sería un gran avance respecto a la situación actual.

El valor ajustado corresponde al valor de una empresa en marcha dividido por el número total de acciones suscritas y pagadas de la sociedad. En circunstancias normales, este último dato debiera ser fácil de obtener; no así el primero. El valor de un bien es determinado por lo que alguien está dispuesto a pagar por él ${ }^{64}$. Sin embargo, dado que la sociedad no quiere, sino que debe comprar las acciones, es necesario establecer ciertas pautas tuitivas del accionista disidente para determinar el precio que estaría dispuesto a pagar un inversor racional, en nuestro caso, por las acciones. En nuestra opinión, un inversor racional debería estar dispuesto a pagar un precio fijado de mutuo acuerdo (A); en su defecto, el precio de la acción en un mercado fiable (B); $\mathrm{y}$, a falta de los anteriores, un precio determinado conforme a los métodos de valoración financieros usualmente aceptados (C).

\section{A. La libertad de acuerdo entre el accionista disidente y la sociedad}

La preferencia por el precio acordado como regla para determinar el valor ajustado es, por una parte, plenamente coherente con la finalidad de la norma (en la medida que el accionista disidente no esté de acuerdo con la valoración, podrá rechazarla) y, por otra parte, eficiente, al minimizar los costos para las partes del procedimiento de determinación del precio ${ }^{65}$.

62 Carney, W., "Fairness opinions: How fair are they and why should we do nothing about it", en Washington University Law Quarterly, 70, 2, I992, 535.

63 Ibíd., 534 .

64 Wertheimer, B., "The shareholders' appraisal remedy and how courts determine fair value", en Duke Law fournal, 47, 4, I998, 61 3-7 1 5, (1998).

65 Conforme, Nota "A reconsideration of the stock market exception to the dissenting shareholder's right of appraisal”, en The Michigan Law Review Association, 74, I975-1976, Io62; GoETz, J., "A dissent dampened by timing: How the stock market exception systematically deprives public shareholders of fair value", en Fordham fournal of Corporate and Financial Law, I 5, 3, 2009, 783; 
Las razones anteriores explican por qué el favorecimiento de la determinación del precio por la vía de un acuerdo entre los accionistas y la sociedad es una tendencia observable en otros ordenamientos jurídicos.

\section{B. El precio de mercado de las acciones}

En ciertas circunstancias, la cotización bursátil puede reflejar el valor económico de una acción (supra II.A) y, por consiguiente, un inversor racional estará dispuesto a pagar ese precio. Por lo anterior y según antes indicamos, es correcto atender al precio promedio bursátil para determinar el precio a pagar al accionista disidente. Un acierto digno de destacarse de esa fórmula es el alejamiento del período de cálculo de la fecha de la respectiva junta, a fin de aislarlo de cualquier consecuencia (positiva o negativa) derivada del hecho detonante del derecho de retiro $^{66}$.

Sin embargo, el precio promedio bursátil también tiene debilidades. Un mercado puede presentar fallas (asimetrías de información, falta de liquidez, poca profundidad, etc.), de modo que la formación de precios se produce imperfectamente. En ese caso, la cotización no refleja el valor asignado por un inversor racional y, por consiguiente, no puede servir para una adecuada tutela del accionista minoritario.

Por lo anterior, adicionalmente a la restricción vigente de aplicar el precio promedio bursátil solamente a las acciones con presencia bursátil, es necesario depurar la cotización de ciertas distorsiones eventualmente presentes en un mercado - p. ej., el descuento de minoría (I) y el descuento por iliquidez (2)-, razón

Alfaro, J. y Campins, A., "La liquidación del socio que causa baja como consecuencia de sus separación o exclusión", en Revista de Derecho Mercantil, 240, 2001, 442-446; PAz-ArEs, C. y Perdices, A., "Lógica y límites de los descuentos por iliquidez y minoría en la valoración de participaciones sociales", en Revista Española de Capital Riesgo, 2, 20 Iо, 5.

66 Fischel, D., "The appraisal remedy in Corporate Law", en American Bar Foundation Research fournal, 8, 4, I983, 890; Тномрson, R., "Exit, liquidity, and majority rule: Appraisal's role in Corporate Law", en Georgetown Law fournal, 84, I, I I-I4; Wertheimer, B., "The purposes of the shareholders' appraisal remedy", en Tennessee Law Review, 65, I997-I998, 665-666; Armour, J., Hansmann, H. y Kraakman, R., "Agency problems and legal strategies", en Kraakman, R. et al., The Anatomy of Corporate Law. A Comparative and Functional Approach, 2. ${ }^{\text {a }}$ ed., Oxford, Oxford University Press, 2009, 4I ; PUGA VIAL, J., La sociedad anónima y otras sociedades por acciones en el derecho chileno y comparado, t. II, Santiago de Chile, Jurídica de Chile, 20 I4, 355. La repercusión en el precio de mercado de los efectos del hecho detonante del derecho de retiro es precisamente la crítica formulada a la denominada Stock Market Exception (Goetz, J., "A dissent dampened by timing: How the stock market exception systematically deprives public shareholders of fair value", en Fordham fournal of Corporate and Financial Law, I 5, 3, 2009, 783); Korsmo, C. y Myers, M., "Appraisal arbitrage and the future of public company M\&A", en Washington University Law Review, 92, 6, 2015, I606-1607. 
por la cual el precio promedio bursátil debe entenderse como una presunción simplemente legal del valor ajustado (3), según explicaremos seguidamente ${ }^{67}$.

\section{La improcedencia del descuento por minoría}

El descuento por minoría es un "descuento por falta de control aplicable a los titulares de un interés minoritario (esto es, inferior al 50\% de los derechos a voto)" ${ }^{\prime 6}$. El precio de cotización de una empresa con capital concentrado naturalmente refleja un descuento por minoría como contrapartida del reconocimiento de una plusvalía a las acciones de control de la sociedad (premio de control). En nuestra opinión, permitir el descuento por minoría en el cálculo del valor ajustado atenta contra el interés protegido por el derecho de retiro, pues altera la medición del valor de la empresa como un todo reflejado en cada acción en fracciones equivalentes ${ }^{69}$.

A favor del rechazo del descuento de minoría como elemento de cálculo del valor ajustado militan varios argumentos. El descuento por minoría, si bien concuerda con la lógica de las operaciones voluntarias de mercado (transacciones externas), es incompatible con el carácter forzoso del derecho de retiro para la sociedad (transacción interna). Como convincentemente se ha sostenido, existe la tentación, por simplicidad, de trasladar la lógica del mercado a las operaciones forzosas, entre ellas, la determinación del precio a pagar al accionista disidente ${ }^{7 \circ}$. Sin embargo, una adecuada tutela del accionista disidente exige construir dife-

67 No abordaremos en este trabajo otros mecanismos de formación de precios (p. ej., una subasta privada dirigida a un grupo amplio de interesados) que pueden servir para determinar el precio a pagar por la sociedad.

68 Traducción libre de la definición contenida en International Glossary of Business Valuation Terms, American Institute of Certified Public Accountants, 20I3, disponible en: https://www.aicpa. org/InterestAreas/ForensicAndValuation/Membership/DownloadableDocuments/Intl\% 20 Glossary\% 20of\% 20BV\% 20Terms.pdf [consultado el 23 de octubre de 2017 ].

69 Explícitamente en ese sentido, Model Business Corporation Act \$ I 3.OI(4) (iii), American Bar Association, 2010 , disponible en: https://apps.americanbar.org/dch/committee.cfm? com=CL2 70000 [consultado el 23 de octubre de 2017 ]. En la doctrina, Wertheimer, B., "The purposes of the shareholders' appraisal remedy”, en Tennessee Law Review, 65, I997-I998, 648 y nota I65; Moll, D., "Shareholders oppression and 'fair value': Of discounts, date, and dastardly deeds in the close corporations", Duke Law fournal, 54, 2, 2004, 3 I 8; Hunter, C. y Pearce, C., "Corporate governance: Voting rights and majority rules", Annual Review of Civil Litigation, 20 I I, 39-40, citando jurisprudencia; Rojo, Á., "Transmisión 'mortis causa' de acciones y participaciones sociales", en Anales de la Academia Matritense del Notariado, t. 54, 20 I3, 43, nota 35, citando jurisprudencia; Paz-Ares, C. y Perdices, A., "Lógica y límites de los descuentos por iliquidez y minoría en la valoración de participaciones sociales", en Revista Española de Capital Riesgo, 2, 20 Iо, 3-I9; Alfaro, J. y Campins, A., "La liquidación del socio que causa baja como consecuencia de sus separación o exclusión”, en Revista de Derecho Mercantil, 24O, 200 I, 474. En contra, Hamermesh, L. y Wachter, M., "The short and puzzling life of the 'implicit minority discount' in Delaware appraisal Law", University of Pennsylvania Law Review, 2007, 50-56.

70 Moll, D., "Shareholders oppression and 'fair value': Of discounts, date, and dastardly deeds in the close corporations", Duke Law fournal, 54, 2, 2004, 319-325; PAZ-Ares, C. y Perdices, A., 
renciadamente el precio a pagar en una transacción externa y en una transacción interna. Importa una contradicción con el interés jurídico tutelado castigar al accionista disidente en consideración a si es minoritario. En ese sentido, el deber de los accionistas de ejercer los derechos sociales respetando los de los demás accionistas (art. 30 LSA) avala la aplicación de una repartición estrictamente proporcional del valor de la empresa como un todo entre los accionistas, sin importar las posiciones relativas (accionista mayoritario o minoritario) ${ }^{7 \mathrm{I}}$.

Así lo ha declarado la Corte Suprema del Estado de Delaware:

Discounting individual share holdings injects into the appraisal process speculation on the various factors which may dictate the marketability of minority shareholdings. More important, to fail to accord to a minority shareholder the full proportionate value of his shares imposes a penalty for lack of control, and unfairly enriches the majority sharebolders who may reap a windfall from the appraisal process by cashing out a dissenting sharebolder, a clearly undesirable result $7^{72}$.

Adicionalmente, el descuento por minoría es incompatible con el carácter disolutivo del derecho de retiro. En efecto, en la liquidación cada accionista recibe repartos a prorrata del número de acciones inscritas a su nombre en el registro de accionistas ( $e x$ art. I I 7.III LSA $)^{73}$. Se trata de restituir a cada accionista la participación correspondiente en el capital social y, si es el caso, en las utilidades no repartidas, siguiendo para esa distribución exclusivamente la proporción de participación en el capital social. Así, por ejemplo, si una sociedad tiene un único bien cuyo valor de realización alcanza la suma de cien millones de pesos y solo dos accionistas, con un 90\% y un I0\%, respectivamente, de las acciones, la distribución será de 90 y ro millones de pesos, respectivamente. Por consiguiente, cada accionista recibirá la proporción correspondiente a la participación en el capital social, sin importar si se trata de un accionista minoritario o mayoritario.

"Lógica y límites de los descuentos por iliquidez y minoría en la valoración de participaciones sociales", en Revista Española de Capital Riesgo, 2, 20 Iо, 7.

7 I En la doctrina española prima esta opinión, según nos informan PAz-Ares, C. y Perdices, A., "Lógica y límites de los descuentos por iliquidez y minoría en la valoración de participaciones sociales”, en Revista Española de Capital Riesgo, 2, 20 го, Iо.

72 Cavalier Oil Corp v. Harnett, 564 A.2d, I I 37 (Del. S.C. I 989). La importancia de esta sentencia es destacada por la doctrina estadounidense: cfr. Wertheimer, B., "The shareholders' appraisal remedy and how courts determine fair value", en Duke Law Journal, 47, 4, I998, 666.

73 Salvo la existencia de acciones cuya preferencia consista en una regla de distribución distinta. Conforme, Puelma, A., Sociedades, 3. ${ }^{\mathrm{a}}$ ed., t. iI, Santiago de Chile, Jurídica de Chile, 2003, 7 Io; Puga VIaL, J., La sociedad anónima y otras sociedades por acciones en el derecho chileno y comparado, $\mathrm{t}$. II, Santiago de Chile, Jurídica de Chile, $2014,829$. 
En otras palabras, la liquidación (total o parcial) establece una regla de distribución sin atender a la lógica del mercado 74 .

Por último, se ha sostenido con acierto que la referencia al precio de mercado carece de justificación para el caso de producirse la disminución del capital social a consecuencia de la adquisición de las acciones del accionista disidente por parte de la sociedad (ex art. 27.III LSA). En ese caso, no se advierte razón por la cual el carácter minoritario del accionista disidente deba repercutir en la determinación del precio a pagar por la sociedad 75 .

\section{La improcedencia del descuento por iliquidez}

El descuento por iliquidez es un "monto o porcentaje deducido del valor del activo por la relativa falta de mercado" 7 .

Los argumentos ofrecidos para negar la procedencia del descuento por minoría son igualmente válidos para comprobar el desacierto de aplicar el descuento por iliquidez para el cálculo del valor ajustado77. Dado que la compraventa de las acciones de un accionista disidente por parte de la sociedad es un contrato forzoso (transacción interna), queda al margen de la lógica del mercado, donde confluyen voluntariamente oferentes y demandantes (transacción externa). Asimismo, la naturaleza disolutiva del derecho de retiro impide atender al descuento de iliquidez como un factor relevante para calcular la cuota de liquidación (en nuestro caso, el precio a pagar por el derecho de retiro).

A los argumentos anteriores es posible agregar otro: si se aplica el descuento por iliquidez en el cálculo del precio a pagar al accionista disidente no solo se estaría perjudicando a este $-\mathrm{y}$, de paso, atentando contra la finalidad de la norma en estudio- sino que se beneficiaría a los otros accionistas (mayoritarios). En un mercado ilíquido, las participaciones mayoritarias son más líquidas que las participaciones minoritarias. Si ello es cierto, los demás accionistas (distintos al disidente) verán proporcionalmente aumentada su participación en el capital social como consecuencia de la amortización de las acciones del accionista disidente y,

74 Paz-Ares, C. y Perdices, A., "Lógica y límites de los descuentos por iliquidez y minoría en la valoración de participaciones sociales", en Revista Española de Capital Riesgo, 2, 20 Iо, 7.

75 Moll, D., "Shareholders oppression and 'fair value': Of discounts, date, and dastardly deeds in the close corporations", en Duke Law fournal, 54, 2, 2004, 345-348; PAZ-Ares, C. y Perdices, A., "Lógica y límites de los descuentos por iliquidez y minoría en la valoración de participaciones sociales", en Revista Española de Capital Riesgo, 2, 20 Iо, I 2.

76 Traducción de la definición contenida en el glosario del American Institute of Certified Public Accountants (2013).

77 Explícitamente, Model Business Corporation Act \$ I 3.or(4) (iii), American Bar Association, 20 Io, disponible en: https://apps.americanbar.org/dch/committee.cfm? com=CL2 70000 [consultado el 23 de octubre de 2017 ]. 
de esa forma, la liquidez de sus acciones crecerá, de la mano de la valoración de las mismas, conforme a las reglas de $\operatorname{mercado}^{78}$.

\section{El carácter de presunción simplemente legal del precio promedio bursátil}

Las depuraciones necesarias en ciertas ocasiones al precio promedio bursátil derivadas de fallas de mercado, aconsejan no establecer una identidad entre este y el valor ajustado a pagar al accionista disidente, sino simplemente una presunción legal: esto es, una estimación abonada a favor de considerar el precio promedio bursátil como el valor ajustado para las acciones con presencia bursátil79.

La asignación al precio promedio bursátil del carácter de presunción simplemente legal del valor ajustado simplifica la determinación del precio a pagar, pero agrega la posibilidad de desafiar ese valor por parte del accionista disidente, si las circunstancias del caso lo ameritan ${ }^{8 \circ}$. Un ejemplo puede ilustrar el punto. Supóngase que un hecho esencial relevante para el valor de la empresa ha sido reservado por el directorio (ex art. IO.III LMV), dándolo a conocer con posterioridad al período relevante para el cálculo del precio. En ese caso, el precio promedio bursátil no constituye un indicador fiable del valor ajustado de la sociedad y, por consiguiente, debe existir un mecanismo para corregirlo.

\section{La deferencia a la lex artis financiera}

A falta de acuerdo entre las partes, el valor ajustado debe determinarse, en un proceso jurisdiccional, según los métodos de valuación de empresas en marcha mayormente aceptados al tiempo del ejercicio del derecho de retiro, cuya elaboración y aplicación corresponde a las ciencias económicas y financieras, y que varían con el tiempo ${ }^{8 \mathrm{r}}$. En la actualidad, la práctica financiera más reputada es la valoración conforme al valor presente de los flujos de caja futuros de una empresa, aunque, dependiendo del tipo de firma o la industria, otros métodos de valoración financiera pueden ser utilizados como forma de comprobación, ajuste o alternativa del DCF (supra II.B).

78 Moll, D., "Shareholders oppression and 'fair value': Of discounts, date, and dastardly deeds in the close corporations", en Duke Law Fournal, 54, 2, 2004, 330-33 I; PAZ-Ares, C. y Perdices, A., "Lógica y límites de los descuentos por iliquidez y minoría en la valoración de participaciones sociales", en Revista Española de Capital Riesgo, 2, 2010, I 7.

79 Nota "A Reconsideration of the Stock Market Exception to the Dissenting Shareholder's Right of Appraisal", The Michigan Law Review Association, 74, I975-1976, 1063.

80 A favor de reconocer el carácter de presunción al valor promedio de cotización bursátil, ibíd., I043.

8I Existe consenso en este sentido, especialmente a partir de Weinberg v. UOP, Inc., 457 A.2d 70 I (Del. S.C. I983); Hunter, C. y Pearce, C., "Corporate governance: Voting rights and majority rules", en Annual Review of Civil Litigation, 20 I I, 33. 
El cálculo del valor ajustado debe realizarse conforme a los métodos financieros generalmente aceptados para la medición del valor de una empresa en marcha en el momento de la valoración. Actualmente la literatura financiera hace primar el valor presente de los flujos de caja futuros de una empresa, pero nada impide que ello cambie en el futuro. Si ese cambio sucede, naturalmente, el valor ajustado debe determinarse de acuerdo al mejor método en ese momento disponible.

\section{El valor ajustado como instrumento de mejora del gobierno corporativo}

\section{A. La contribución del valor ajustado a un mejor gobierno corporativo}

Antes hemos mencionado la utilidad del derecho de retiro para mitigar el problema de agencia entre accionistas mayoritarios y minoritarios, especialmente en sociedades con capital concentrado, erigiéndose como un mecanismo de protección del accionista minoritario frente a eventuales abusos de la mayoría (supra I). También señalamos que la estructura corporativa de nuestra sociedad anónima abierta presenta una alta tasa de concentración y, por consiguiente, el problema de agencia entre accionistas mayoritarios y minoritarios es omnipresente. En suma, el derecho de retiro funge en nuestra legislación como uno de los principales mecanismos de tutela del accionista minoritario ${ }^{82}$.

El régimen vigente de determinación del precio a pagar por la sociedad, las más de las veces, perjudica al accionista disidente. La contribución a la mejora del gobierno corporativo de una sociedad anónima abierta de nuestra propuesta de determinación del precio a pagar conforme al valor ajustado apunta a corregir la falta de coherencia interna entre el interés tutelado y la regla de cálculo del valor de las acciones. De esa forma, la posición del accionista minoritario será (no solo en el papel, sino) realmente fortalecida, incentivando a los administradores (de hecho o de derecho) a una toma de decisiones orientada a un mejor balance de los distintos intereses en juego en el momento de realizar una reforma sustantiva del estatuto social, disminuyendo ex ante el costo de financiamiento de las sociedades anónimas cotizadas y aumentando la eficiencia en la asignación de recursos a través del mercado de valores.

82 Esta decisión de política jurídica es evidente si se recuerda la ausencia de un régimen de impugnación de las decisiones de la junta de accionistas y la significativa ampliación del catálogo de causales del derecho de retiro como mecanismo de tutela del accionista minoritario (Biblioteca del Congreso Nacional de Chile, "Historia de la Ley 1 9.705", 5, 281, 302 y ro35, disponible en: https://www.leychile.cl/Navegar?idNorma $=179295 \&$ buscar $=19705$ [consultado el 23 de octubre de 20I 7]; PUGA VIAL, J., La sociedad anónima y otras sociedades por acciones en el derecho chileno y comparado, t. II, Santiago de Chile, Jurídica de Chile, 2014,2 Io. 
Por todo lo anterior, la incorporación en nuestro ordenamiento de la noción de valor ajustado en sí misma constituye una herramienta de mejora del gobierno corporativo.

\section{B. Hacia un mercado de derechos de retiro para las sociedades anónimas abiertas}

El gobierno corporativo de una sociedad anónima abierta puede beneficiarse de la existencia de un mercado de derechos de retiro, de la misma manera que con un mercado por el control societario ${ }^{8}$. Como es bien sabido, si el valor de las acciones decae debido a una mala administración, llegará un punto en que otros inversores tomarán el control de la sociedad y reemplazarán a la actual administración ${ }^{84}$. De modo similar, un mercado de derechos de retiro disciplinaría a los administradores: si el precio ofrecido por la sociedad al accionista disidente es inferior al valor ajustado en un monto suficiente para hacer atractivo impugnarlo, entonces un inversor no-accionista estará interesado en adquirir acciones de la sociedad, ejercer el derecho de retiro e impugnar el valor ajustado ofrecido, a fin de capturar la diferencia entre el valor que se ofrece pagar y el valor ajustado.

La existencia de ese mercado de derechos de retiro requiere (entre otras reformas ${ }^{85}$ ) un ajuste en las reglas vigentes de legitimación para el ejercicio del derecho de retiro. Este consiste en eliminar la exigencia de inscripción en el registro de accionistas a la fecha del hecho generador del derecho de retiro, por una parte, y, por otra, extender la legitimación para quienes adquieran acciones de la sociedad hasta después de transcurridos 6o días desde el hecho o el acuerdo de la junta de accionistas respectivo ${ }^{86}$. Ese plazo se considera suficiente para que inversores no-accionistas puedan evaluar si el precio ofrecido por la sociedad es consistente con el valor ajustado de las acciones con la información pública disponible.

La ampliación de la legitimación a los adquirentes de acciones con posterioridad al nacimiento del derecho de retiro puede considerarse inadecuada por

83 De la experiencia en Delaware nos informa Korsmo, C. y Mrers, M., "Appraisal arbitrage and the future of public company M\&A", en Washington University Law Review, 92, Issue 6, 2015, I 557 y I 598 .

84 Easterbrook, F. y Fischel, D., The Economic Structure of Corporate Law, Cambridge, Harvard University Press, I99 I, I I 2-I I 7 .

85 El desarrollo de la arquitectura procesal de la determinación del precio en coherencia con la búsqueda de la formación de un mercado de derechos de retiro (probablemente por medio de una class action a favor de los accionistas disidentes) es una cuestión que, debido a su extensión, reservamos para un futuro estudio.

86 Un plazo breve, si se compara con el de I 20 días establecido en el Estado de Delaware $(\$ 262$ Apraissal Rights, letter (e), Subchapter IX. Merger, Consolidation or Conversión, Title 8: Corporations, The Delaware Code). Esta modificación del plazo exige, a su turno, ajustar otras normas (como, p. ej., el plazo de pago las acciones) no abordadas en este trabajo. 
reconocer el derecho de retiro a favor de quien no sufrió la opresión de la mayoría. Esa objeción pierde fuerza si se considera que el efecto disuasivo de esta ampliación de la legitimación pretende mejorar la tutela de los accionistas en el momento del nacimiento del derecho de retiro. En efecto, si la administración sabe que el precio ofrecido será analizado por el mercado, existirán fuertes incentivos para realizar una oferta consistente con el valor ajustado.

Se sientan así las bases para un mercado de derechos de retiro que, al igual que el mercado de control, pueda disciplinar a los administradores (de hecho o de derecho) de una sociedad anónima abierta a ofrecer, desde un comienzo, al accionista disidente el pago de una suma coincidente con el valor ajustado, mitigando de esa forma los problemas de agencia, especialmente acusados en una sociedad con capital concentrado.

Esa (nueva) dinámica del derecho de retiro fortalecería los derechos de los accionistas minoritarios, quienes estarían dispuestos a pagar más por esas acciones y, en consecuencia, disminuiría el costo de financiamiento de la sociedad, existiendo mayores incentivos para la inversión por parte de los mismos ${ }^{87}$. Este nuevo equilibro entre los distintos intereses en juego generaría mayor valor para todos ellos, mejorándose el gobierno corporativo de nuestras sociedades.

\section{Referencias}

Agosin, M. y PAstén, E., "Corporate governance in Chile”, Documentos de Trabajo, Banco Central de Chile, 209, 2003.

Alcalde, E., "Resolución parcial y exclusión de un accionista en la sociedad anónima", en El Mercurio Legal, 2014, disponible en: http://www.elmercurio.com/Legal/Noticias/ Analisis-Juridico/2OI4/03/o3/Resolucion-parcial-y-exclusion-de-un-accionista-enla-sociedad-anonima.aspx [consultado 23 de octubre de 20I 7 ]

Alfaro, J. y Campins, A., "La liquidación del socio que causa baja como consecuencia de sus separación o exclusión”, en Revista de Derecho Mercantil, n. ${ }^{\circ}$ 240, 200 I, 44I-493.

Allen, W., "Securities markets as social products: The pretty efficient capital market hypothesis", en The fournal of Corporation Law, 28, n. ${ }^{\circ}$ 4, 2003,55 I-563.

American Bar Association, Model Business Corporation Act, 2010 , disponible en: https:// apps.americanbar.org/dch/committee.cfm? com=CL270000 [consultado 23 de octubre de 2017$]$.

American Institute of Certified Public Accountants, "International Glossary of Business Valuation Terms", 20I3, disponible en: https://www.aicpa.org/InterestAreas/ForensicAndValuation/Membership/DownloadableDocuments/Intl\% 2oGlossary $\%$ 20of\% $20 \mathrm{BV} \%$ 20Terms.pdf [consultado 23 de octubre de 2017 ].

87 Korsmo, C. y Myers, M., "Appraisal arbitrage and the future of public company M\&A", Washington University Law Review, 92, 6, 201 5, I599. 
Armour, J., Hansmann, H. y Kraakman, R., "Agency problems and legal strategies", en Krankman, R. et al., The Anatomy of Corporate Law. A Comparative and Functional Approach, 2. ${ }^{a}$ ed., Oxford, Oxford University Press, 2009, 35-52.

Armour, J., Hansmann, H. y Kraakman, R., "What is Corporate Law", en Kraakman, R. et al., The Anatomy of Corporate Law. A Comparative and Functional Approach, 2. " ed., Oxford, Oxford University Press, 2009, I-34.

Barberis, N. y Thaler, R., "A survey of behavioral finance", en Constantinides, G. et al. (eds.), Handbook of the Economics of Finance, 2, Elsevier, 2003, parte B, cap. I8, I053-I I 28.

Beck, T. y Levine, R., "Stock markets, banks, and growth: Panel evidence", en fournal of Banking \& Finance, 28, 3, 2004, 423-442.

Benston, G., "Accounting numbers and economic values", en Antitrust Bulletin, 27, I982, I6I-2 I 5 .

Berger, P. y Ofek, E., "Diversification's effect on firm value”, en fournal of Financial Economics, 37, I, 39-65.

Bernet, M., "El gobierno de las sociedades abiertas", en Revista de Derecho (Valdivia), 9, disponible en: http://www.scielo.cl/scielo.php?script=sci_arttext\&pid=So7 I 809502004000100002\&lng=es\&nrm= iso\&tlng=es [consultado 23 de octubre de $2017]$.

Biblioteca del Congreso Nacional de Chile, "Historia de la Ley n. ${ }^{\circ}$ i 9.705", 20 de diciembre de 2000, disponible en: https://www.leychile.cl/Navegar?idNorma=I 792 95 \&buscar $=19.705$ [consultado 23 de octubre de 201 7 ].

Biblioteca del Congreso Nacional de Chile, "Historia de la Ley n. ${ }^{20}$. 382 ", 20 de octubre de 2009, disponible en: https://www.leychile.cl/Navegar?idNorma=100729 $7 \&$ buscar $=20382$ [consultado 23 de octubre de 2017].

Black, B. y Kraakman, R., "A self-enforcing model of Corporate Law", en Harvard Law Review, 109, 1996, г91 г-1982.

Brudney, V., (I978-I979), "Efficient markets and fair values in parent subsidiary mergers", en The Fournal of Corporation Law, 4, I978-1979, 63-86.

Carney, W., "Fairness opinions: How fair are they and why should we do nothing about it", en Washington University Law Quarterly, 70, 2, 1992, 523-540.

Carney, W., "Fundamental corporate changes, minority shareholders, and business purposes", en American Bar Foundation Research Fournal, 5, I, I980, 69-1 32.

Claessens, S. y Yurtoglu, B., "Corporate governance in emerging markets: A survey", en Emerging Markets Review, I 5, 201 3, I-33.

Clarke, T., Theories of Corporate Governance. The Philosophical Foundations of Corporate Governance, New York, Routledge, reimp., 2007.

Cohen, D., "Valuation in the context of share appraisal", en Emory Law Fournal, 34, I, I 985 , I I 7-I 56.

Contreras, R., “Gobierno, gestión y ética corporativa: análisis y recomendaciones”, memoria de prueba, Universidad de Chile, inédita, 2005. 
Dasso, A., Tratado del derecho de separación o receso del socio y del accionista, Buenos Aires, Legis, 2012.

Deloof, M., De Maeseneire, W. y Inghelbrecht, K., "How do investment banks value initial public offerings (IPOs)?”, en Fournal of Business Finance \& Accounting, 36 6, n. ${ }^{\circ}$ I-2, 2009, I $30-$ I 60 .

Demsetz, H., The Economics of the Business Firm, Cambridge, Cambridge University Press, I997.

Easterbrook, F. y Fischel, D., "Shareholder voting rights and the exercise of voice", en The Fournal of Law and Economics, 26, 1983, pp. 395-427.

Easterbrook, F. y Fischel, D., The Economic Structure of Corporate Law, Cambridge, Harvard University Press, I99I.

Eyzaguirre, C., "Introducción al 'corporate governance”, memoria de prueba, Universidad de Chile, inédita, 200 I.

FAma, E., "Efficient capital markets: A review of theory and empirical works", en The fournal of Finance, 25, 2, 1969, 383-41 7.

Fernández, P., "Company valuation methods. The most common errors in valuations", en IESE Business School, University of Navarra, 2013, disponible en: https://is.vsfs. cz/el/64ro/leto2or4/N_OP/um/Fernandez_2OI3_Company_Valuation_Methods_ SSRN-id2 74973.pdf [consultado 23 de octubre de 20I 7 ].

Fischel, D., "Efficient capital markets, the crush, and the fraud on the market theory", en Cornell Law Review, 74, I988-1989, 907-922.

Fischel, D., "The appraisal remedy in Corporate Law", en American Bar Foundation Research fournal, 8, 4, I983, 875-904.

G20/oecD, Principles of Corporate Governance, Paris, oECD, 2015, disponible en: http:// www.iadb.org/res/laresnetwork/files/pr2 2 Ifinaldraft.pdf [consultado el 23 de octubre de 20I7].

García Pino, G. y Contreras, P., "El derecho a la tutela judicial y al debido proceso en la jurisprudencia del Tribunal Constitucional chileno", en Estudios Constitucionales, II, n. ${ }^{\circ}$ 2, 20I3, pp. 229-282.

Gilson, R. y Kraakman, R., "The mechanisms of market efficiency", en Virginia Law Review, 70, n. ${ }^{\circ}$ 4, I984, 549-644.

Goetz, J., "A dissent dampened by timing: How the stock market exception systematically deprives public shareholders of fair value", en Fordham fournal of Corporate and Financial Law, I 5, n. ${ }^{\circ}$ 3, 2009, 77 I-806.

Gordon, M. y Shapiro, E., "Capital equipment analysis: The required rate of profit", en Management Science, 3, n. $^{\circ}$ I, I956, IO2-I IO.

Hamermesh, L. y Wachter, M., "The short and puzzling life of the 'implicit minority discount' in Delaware appraisal Law", en University of Pennsylvania Law Review, 2007, I-6I.

Harbula, P., "Valuation multiples: Accuracy and drivers evidence from the european

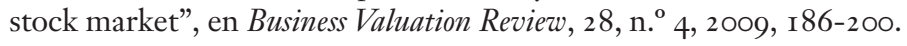


Harris, M. y Raviv, A., "Corporate governance: Voting rights and majority rules", en Fournal of Financial Economics, 20, I988, 203-235.

Hernández, L. y Parro, F., "Sistema financiero y crecimiento económico en Chile”, en Revista de Estudios Públicos, n. ${ }^{\circ} 99,2005,97-$ I 34.

Hull, J., Options, Futures and Other Derivatives, New Jersey, Prentice Hall, 2009.

Hunter, C. y Pearce, C., "Corporate governance: Voting rights and majority rules”, en Annual Review of Civil Litigation, $201 \mathrm{I}, 25-72$.

Isla, G., "Gobierno corporativo: Teoría económica, principios de la ocde y la Ley n. ${ }^{\circ}$ 20.382", en Wilenmann, J. (coord.), Gobiernos corporativos, Santiago de Chile, Thomson Reuters, 20 I I, 9-44.

Kanda, H. y Levmore, S., "The appraisal remedy and the goals of Corporate Law", en UCLA Law Review, 32, I984-1985, 429-473.

Kaplan, S. y Ruback, R., “The valuation of cash flow forecasts: An empirical analysis”, en The Fournal of Finance, 50, n. ${ }^{\circ}$ 4, 1995, 1059-1093.

Kearney, C., "Emerging markets research: Trends, issues and future directions", en Emerging Markets Review, I 3, n. ${ }^{\circ}$, 201 2, I $32-159$.

Kim, M. y Ritter, J., "Valuing ipos", en Fournal of Financial Economics, 53 n. ${ }^{\text {o }}$ 3, I999, 409-437.

Klapper, L. y Love, I., "Corporate governance, investor protection, and performance in emerging markets", en Fournal of Corporate Finance, Io, 5, 2004, 703-728.

Koller, T., Goedhart, M. y Wessels, D., "The right role of multiples in valuation”, en McKinsey on Finance, I 5, 2005, 7-I I.

Koller, T., Goedhart, M. y Wessels, D., Valuation: Measuring and Managing the Value of Companies, New Jersey, Wiley, 2 о го.

Korsmo, C. y Myers, M., "Appraisal arbitrage and the future of public company M\&A", en Washington University Law Review, 92, 6, 201 5, I 55 I-I6I 5.

La Porta, R., López De Silanes, F., Schleifer, A. y Vishny, R., "Legal determinants of external finance", en Fournal of Finance, $5^{2}$, n. $^{\circ} 3$, I 997 , I I 3 I-I I 5 O.

Lefort, F. y Walker, E., “Ownership and capital structure of Chilean conglomerates fact and hypothesis in Chile", Revista Abante, I, 2000, 7 .

Lefort, F. y Walker, E., "The effect of corporate governance practices on company market valuation and payout policy in Chile", Research Network Working Paper, Inter-American Development Bank, 2005, I6, disponible en: http://www.iadb.org/ res/laresnetwork/files/pr2 2 I finaldraft.pdf [consultado 23 de octubre de 2017 ]

Levine, R., "Finance and growth: Theory and evidence", en Aghion, P. y Durlauf, S., (eds.), Handbook of economic growth, I, Elsevier, 2005, 865-934.

LiE, E. y LiE, H., "Multiples used to estimate corporate value", en Financial Analysts fournal, 58, n. $^{\circ}$, $2002,44^{-54}$.

Liv, J., Nissim, D. y Thомas, J., "Equity valuation using multiples”, en fournal of Accounting Research, 40, n. ${ }^{\circ}$ I, 2002, I $35^{-1} 7^{2}$.

López, J., Los contratos, Santiago de Chile, Jurídica de Chile, 2005. 
Majluf, N. Abarca, Rodríguez, D. y Fuentes, L., "Governance and ownership structure in Chilean economic groups", Revista Abante, I, I 998, I I I-I I 5.

Manning, B., "The shareholder's appraisal remedy: An essay for Frank Coker", en Yale Law fournal, 72, 1962, 223-261.

Modigliani, F. y Miller, M., "The cost of capital, corporation finance and the theory of investment", en The American Economic Review, 48, n. ${ }^{3}$, I958, 26 I-297.

Moll, D., "Shareholders oppression and 'fair value': Of discounts, date, and dastardly deeds in the close corporations", en Duke Law Fournal, 54, n. ${ }^{\circ}$ 2, 2004, 293-383.

Muñoz, A., "Determinación del valor razonable de las acciones por un tercero, en el caso de restricción estatutaria a la transmisibilidad inter-vivos", en Revista de Derecho de Sociedades, n. ${ }^{\circ}$ 25, 2005, 297-304.

Niño, J. y Rivas, C., "La razón valor en libros-valor de mercado: el caso chileno", en Análisis Económico, I9, n. ${ }^{\circ}$ 42, 2004, I 50-1 86.

Nota "A reconsideration of the stock market exception to the dissenting shareholder's right of appraisal", en The Michigan Law Review Association, 74, I975-1976, 1023Io66.

Olavarría, J., Manual de derecho comercial, Barcelona, Clarasó, I969.

Paz-Ares, C. y Perdices, A., "Lógica y límites de los descuentos por iliquidez y minoría en la valoración de participaciones sociales", en Revista Española de Capital Riesgo, n. ${ }^{\circ}$ 2, 2010, 3-I9.

Pereiro, L., "The valuation of closely-held companies in Latin America”, en Emerging Markets Review, 2, 4, 2001, 330-370.

Puelma, A., Sociedades, 3. . ed., Santiago de Chile, Jurídica de Chile, 2003.

Puga VIAL, J., La sociedad anónima y otras sociedades por acciones en el derecho chileno y comparado, Santiago de Chile, Jurídica de Chile, 2014.

Rock, E., Davies, P., Hideki, K. y Kraakman, R., "Fundamenatl changes", en Kraakman, R. et al., The Anatomy of Corporate Law. A Comparative and Functional Approach, 2. ${ }^{\mathrm{a}}$ ed., Oxford University Press, Oxford, 2009, I83-224.

Rojo, Á., “Transmisión 'mortis causa' de acciones y participaciones sociales”, en Anales de la Academia Matritense del Notariado, t. 54, 2013 , I 3-56.

Romano, R., Foundations of Corporate Law, New York, Foundation Press, I993.

Sánchez Andrés, A., “Cotización De Valores”, en Sáenz, J., Oleoo, F. y Martínez, A., (eds.), Estudios jurídicos sobre el mercado de valores, Cizur Menor, Thomson-Civitas, $2008,83 \mathrm{I}-84^{2}$.

Shleifer, A. y Vishny, R., "A survey of corporate governance", en The fournal of Finance, 52, 2, I $997,737-783$.

Shleifer, A. y Wolfenzon, D., "Investor protection and equity markets", en fournal of Financial Economics, 66, I, 2002, 3-2 7.

Thompson, R., "Exit, liquidity, and majority rule: Appraisal's role in Corporate Law", en Georgetown Law Journal, 84, n. ${ }^{\circ}$, , 1995, I-60. 
Wertheimer, B., “The purposes of the shareholders' appraisal remedy”, en Tennessee Law Review, 65, I997-1998, 66 I-690.

Wertheimer, B., "The shareholders' appraisal remedy and how courts determine fair value", en Duke Law Fournal, 47, 4, I998, 613-71 5.

World Bank, Corporate Governance Country Assessment Chile, Report on the Observance of Standards and Codes, 2003, 2, disponible en: https://openknowledge.worldbank.org/ handle/I0986/I 4493 [consultado 23 de octubre de 2017].

Yermack, D., "Higher market valuation of companies with a small board of directors", en Fournal of Financial Economics, 40, 2, I996, I8 5-2 I I. 